\title{
ENTRE EL OCIO Y LA NECESIDAD: LA PRÁCTICA DE LA CAZA EN EL BURGOS DEL SETECIENTOS
}

\section{Between Leisure and Need: The Practice of Hunting in the Burgos of the Eighteenth Century}

\author{
Francisco SANZ DE LA HIGUERA \\ sanzdelahiguera@gmail.com
}

Fecha de recepción: 25/03/2019

Fecha de aceptación definitiva: 27/12/2019

RESUMEN: En las viviendas de los burgaleses del siglo XVIII, los escribanos se topaban, a la hora de efectuar la descripción de sus enseres y pertrechos, con armas de fuego -escopetas, trabucos, arcabuces, carabinas y fusiles- que, eventualmente, podían ser utilizadas para la práctica de la caza, sea como instrumento de ocio o como herramienta para cubrir, en la medida de lo posible, la necesidad de buscar alimentos cárnicos con que completar la dieta. ¿Existen notorias diferencias entre las categorías socioprofesionales a este respecto? ¿Su devenir a lo largo de la centuria experimentó un gradual incremento o, por el contrario, una paulatina desaparición?

Palabras clave: caza; escopeta; ocio; necesidad; Burgos; siglo XVIII.

ABSTRACT: In the dwellings of the Burgos inhabitants of the 18th century, the scribes met, at the time of making the description of their equipment and accoutrements, with firearms -shotguns, blunderbusses, harquebuses, carbines and rifles-, which, eventually, could be used for the practice of hunting, either as a leisure tool or as a tool to cover, as far as possible, the need to look for meat foods with which to complete the diet. Are there significant differences between the socio-professional categories in this regard? Did its evolution throughout the century experienced a gradual increase or, on the contrary, a gradual disappearance?

Key words: hunting; shotgun; leisure; necessity; Burgos; 18th century. 


\section{INTRODUCCIÓN, FUENTES DOCUMENTALES Y BIBLIOGRAFÍA}

En las próximas páginas no se va a analizar la presencia, en los inventarios de bienes del siglo XVIII, de alguna "Escovetta" ni de una "Escarpeta" o varias, generalmente de lana ${ }^{2}$, en las viviendas castellanas del Setecientos. En la práctica, estos folios se centran en la disponibilidad de "Escopettas" y de otras armas (largas) de fuego, como trabucos, arcabuces, fusiles y carabinas, en los interiores domésticos burgaleses del siglo XviII. Una lectura defectuosa de dichos vocablos - escobeta, escarpeta o escopeta- puede inflacionar el cómputo a favor de uno u otro término y generar nefastos errores en la cuantificación. Esta prevención no es un aserto inútil ni gratuito. Una lastimosa, y anecdótica, confusión, o incorrecta interpretación de la grafía del escribano, puede generar notorias perturbaciones en la reconstrucción histórica.

Este trabajo se lleva a cabo con el telón de fondo de un artículo anterior ${ }^{3}$, si bien se acomete con un criterio hipercientífico. En una primera instancia, se aventuró un análisis con la recopilación de 400 inventarios de bienes, cronológicamente circunscritos a las décadas centrales del siglo XVIII y a los hogares retratados en el Catastro de Ensenada -en Burgos, confeccionado en el discurso de 1751-. La ampliación de la base documental hasta los 929 inventarios, generalmente post-mortem, hace imprescindible un contraste con los resultados y tesis anteriores, desde el aserto de que lo que se pierde en sincronía se gana, y mucho, en diacronía. En aplicación de las teorías de Karl Popper, en especial a través de sus propuestas en Conjeturas y refutaciones, una de las pretensiones metodológicas y didácticas de estas páginas transita por la realización de un inmisericorde proceso de crítica hacia lo anteriormente formulado. "Al poner de manifiesto nuestros errores [caso de haberlos], nos hace comprender las dificultades del problema que estamos tratando de resolver [...] y de esta manera podemos aprender de nuestros errores. A medida que aprendemos de nuestros errores, nuestro conocimiento aumenta, aunque nunca podamos llegar a saber, esto es, a conocer con certeza ${ }^{4}$. Se plantea, a la postre, una problemática metodológica y epistemológica sobre la influencia que el volumen, y calidad, de la documentación histórica puede ejercer en el análisis y las conclusiones a extraer de una investigación científica.

1. Véase, por ejemplo, el inventario post-mortem [en lo sucesivo IPM] de Mateo Albuerne, tabernero de aguardientes. AHPB. PN. Martín Robredo. Legajo 6969 (4 de abril de 1729), folio 152 (149-152).

2. Véase, por ejemplo, el IPM de Catalina González. AHPB. PN. Jacinto del Río. Legajo 7050/1 (7 de julio de 1726), folio 179 (169-180)

3. Sanz de la Higuera, Francisco. "La caza en el Burgos del Setecientos». Vínculos de Historia, 2015, 4, pp. 251-276.

4. POPPER, Karl. Conjeturas y refutaciones. El desarrollo del conocimiento científico. Barcelona: Paidós, 1991, p. 13. 
¿Multiplicar por 2.4 la disponibilidad de inventarios de bienes invalida o consolida, en la reconstrucción de la cultura material, las anteriores propuestas y reflexiones?

wla expresión aparecida en el post-mortem del mercader de cerería Rafael Igarza $^{5}$, nos aportan unos pormenores de similar calado y calidad. Algunos son excepcionales, aunque la mayoría fueron meras constataciones, sin detalles, de las armas encontradas en las estancias de los difuntos. El efectuado por el escribano Santiago Romo para el aristócrata Juan Antonio María Enríquez es, por lo inusual de sus pormenores, una auténtica joya documental. Dicho individuo era propietario de "Una Escopeta con llave a la Romana echa en Madrid por el Maestro Joseph Cano el año 1731, como consta de sus marcas doradas y letreros", arma tasada en 1.600 reales de vellón ${ }^{6}$. Nada se dice, sin embargo, del tamaño de las armas ni del grano, la guarnición o la llave. Lamentablemente, lo más habitual era la mera constatación, entre los pertrechos del difunto, de "Una escopeta con su llave», como es el caso documentado para, por ejemplo, el labrador Francisco Sáiz ${ }^{7}$.

Si las descripciones efectuadas por Romo para el citado noble rentista estuvieran disponibles igualmente para el restante elenco de armas de caza de los demás vecinos de la ciudad de Burgos en el devenir del Setecientos, las posibilidades de reconstrucción de las prácticas venatorias hubieran sido auténticamente admirables. El asiento de la escopeta de Enríquez significa un escueto $0.8 \%$ de las ocurrencias constadas -véase Cuadro 1-. La norma habitual en los post-mortem burgaleses del Setecientos era que el escribano hiciera mención de las armas largas localizadas con una nula constatación de detalles. En efecto, en el $64.7 \%$ de los hogares con armas de este tipo, el escribano únicamente dejó constancia, sin más, de una o más escopetas -lo mismo se puede decir para los trabucos, los arcabuces, los fusiles o las carabinas-, siempre de una manera escueta y sin más pormenores. En otro 34.5 \%, las descripciones de las escopetas incluyen, y no de forma simultánea, información sobre la procedencia geográfica, las dimensiones del arma o el maestro fabricante. Denominaré a estas «intermedias».

5. Archivo Histórico Provincial de Burgos. Protocolos Notariales [en lo sucesivo AHPB. PN]. Feliciano Medel de Prada. Legajo 7259/4 (28 de junio de 1787), folio 111.

6. También se detallan «Una Escopeta con llave a la española que no es de Maestro conocido, solo la llave dize averse echo en Reinosa” (tasada en 180 reales), varias fundas de escopeta, de badana, "Un frasco de Pólvora de madera del aire color de Concha, errada por el Mro Fco Albarez, según la marca dorada que tiene en el gancho con un cordón de Seda verde» (60 reales) y bolsas con muelle de hierro para la munición. AHPB. PN. Santiago Romo. Legajo 6980 (17 de junio de 1734), folios 75 y 76.

7. AHPB. PN. Agustín del Busto. Legajo 7066/2 (28 de mayo de 1759), folio 181. 


\begin{tabular}{|c|c|c|c|}
\hline CUADRO1 & \multicolumn{3}{|c|}{ ARMAS DE CAZA EN LOS INVENTARIOS } \\
\hline & \multicolumn{3}{|c|}{ DESCRIPCIÓN DEL ARMAMENTO } \\
\hline & NULA & INTERMEDIA & INTENSA \\
\hline HILANDERAS & 100 & & \\
\hline LABRADORES & 71.4 & 28.6 & \\
\hline ARTESANOS & 72.7 & 27.3 & \\
\hline COMERCIANTES & 66.7 & 33.3 & \\
\hline BURÓCRATAS & 56.2 & 43.8 & \\
\hline SERVICIOS PÚBLICOS & 63.1 & 26.9 & \\
\hline NOBLES RENTISTAS & 73.3 & 20 & 6.7 \\
\hline CLÉRIGOS & 66.7 & 33.3 & \\
\hline MILITARES & & 100 & \\
\hline TOTAL BURGOS & 64.7 & 34.5 & 0.8 \\
\hline La totalidad de las expresiones númericas en porcentaje (\%). \\
\hline Fuente documental: AHPB. PN. Múltiples Legajos. & \\
\hline
\end{tabular}

Las armas con menos lujo de detalles -en más del $60 \%$ las descripciones son nulas- las encontramos en los inventarios de las hilanderas (100 \%), los labradores y hortelanos (71.4\%), los artesanos (72.7 \%) y los nobles rentistas (73.3 \%). Ello significa que las menciones intermedias, es decir, con algún detalle característico, son lamentablemente escasas $-28.6 \%$ para las hilanderas, $27.3 \%$ para los artesanos y $20 \%$ para los citados nobles rentistas-. Pedro Carrera, labrador, era propietario de «Una escopeta», tasada en 40 reales $^{8}$. María Fresno, labradora viuda, disponía de «Una Escopeta vizcaína con su cañón y llave», tasada en 12 reales?. Al maestro carpintero Gabriel Pérez se le descubre entre sus pertrechos «Una Escopeta buena", tasada en 40 reales $^{10}$. El maestro batidor de oro José Calvo poseía "Una Escopeta corta de una bara», tasada en 30 reales $^{11}$. El aristócrata Ciriaco Luís Zorrilla Barrenechea disponía de "Una Escopeta»" Agustín Peñas Mendoza, noble rentista, disfrutaba de «Una escopeta de Bartolomé Fernández con sus embutidos y fogón de oro y los mesmo en el guardamonte con su frasco y bolsas", todo ello tasado en 600 reales de vellón ${ }^{13}$.

8. AHPB. PN. Gaspar Tomé González. Legajo 8309 (27 de enero de 1753), folio 242.

9. AHPB. PN. José Fernández Guilarte. Legajo 6899 (17 de octubre de 1708), folio 442.

10. AHPB. PN. José Mata. Legajo 6918 (26 de noviembre de 1706), folio 440.

11. AHPB. PN. Martín Robredo. Legajo 6967 (7 de enero de 1727), folio 160.

12. AHPB. PN. Miguel Palma Valderrama. Legajo 7288/3 (18 de junio de 1796), folio 144

13. AHPB. PN. Juan Antonio Fernández Guilarte. Legajo 7005 (23 de octubre de 1736), folio 597. 
En los inventarios de los comerciantes, los profesionales de los servicios públicos ${ }^{14}$ y los clérigos, las descripciones prácticamente nulas se sitúan entre el 60 y el $70 \%-66.7 \%$ para los comerciantes, $63.1 \%$ para los profesionales y $66.7 \%$ para los eclesiásticos-, lo que mejora el panorama de las menciones intermedias -hasta el $33.3 \%$ en los comerciantes, el $36.9 \%$ en los citados profesionales y el $33.3 \%$ para los clérigos-. El mercader de paños y sedas Manuel Sáinz de Viniegra dejaba reposar en la "Antesala" de su vivienda "Una Escopeta", tasada en 60 reales ${ }^{15}$. Su compadre de trato, Pedro Domínguez de la Torre, usufructuaba «Dos Escopetas de Plasencia", valoradas en 300 reales de vellón ${ }^{16}$. Al mesonero Juan Gamero se le anota "Una Escopeta» de 75 reales ${ }^{17}$. El médico Manuel Balmaseda era propietario de «Una Escopeta, fábrica de Gómez, maestro de Burgos», tasada en 480 reales $^{18}$. Entre los eclesiásticos contrasta la mera escopeta de Luis Salva, sochantre en la Catedral -valorada en 12 reales- ${ }^{19}$, con la magnífica "Escopeta de Bustin Dui, montada a la Romana, con guardamonte de madera, forrado en plata y grano de oro", tasada en 540 reales, del capellán del Hospital de Barrantes, Juan Pérez Ceballos ${ }^{20}$.

Entre los militares, el $100 \%$ de las armas de caza aparecidas en sus inventarios nos aportan detalles significativos. Descuellan, sin duda, las «Espadas y otros Ynstrumentos» del coronel de Infantería y regidor perpetuo Miguel Antonio de la Torre, poseedor de cinco escopetas y un trabuco naranjero. Es imprescindible citar «Una Escopeta de Esquivel, el Mro que fue del Rey, con el grano i marcas de oro, en veinte doblones», valorada en 1.200 reales de vellón ${ }^{21}$. Para los burócratas las descripciones nulas (56.2\%) y las intermedias (43.8 \%) están casi equiparadas. En el inventario post-mortem del escribano Ramón Romero hallamos una mera "Escopeta»-tasada en 16 reales- ${ }^{22}$. El notario receptor de la Audiencia Arzobispal Antonio Sáinz de Tejada era propietario de «Una Escopeta corta de una bara con su llave vizcaína, maltratada», valorada en 20 reales $^{23}$.

Otra cuestión relevante destila de la calidad de las anotaciones de los escribanos. En únicamente el $9 \%$ de los inventarios se significa, de manera explícita, que el armamento estaba destinado a la práctica de la caza. Entiendo que en el otro 91 \% las escopetas y demás armas largas tenían esa dedicación, si bien

14. Médicos, boticarios, cirujanos, barberos, sangradores, mesoneros, posaderos, alquiladores de mulas, obligados de la logística urbana, etcétera.

15. AHPB. JM. Alonso Melo Peña. Legajo 987 (1 de julio de 1786), folio 5.

16. AHPB. PN. Juan Antonio Fernández Guilarte. Legajo 7287 (6 de agosto de 1791), folio 100.

17. AHPB. PN. Julián Álvarez. Legajo 7264 (20 de abril de 1776), folio 358.

18. AHPB. PN. Gil Antonio Merino. Legajo 8314 (20 de diciembre de 1769), folio 576.

19. AHPB. PN. José Merino Vázquez. Legajo 7305 (14 de febrero de 1803), folio 572.

20. Archivo Capitular de la Catedral de Burgos [en adelante ACCB]. Alonso Melo Peña. Libro 133 (10 de enero de 1776), folio 560.

21. AHPB. Justicia Municipal [JM]. Juan Antonio Fernández Guilarte. Legajo 976 (7 de mayo de 1751), folios 19 y 30 .

22. AHPB. PN. Manuel Castro García. Legajo 7300/1 (11 de febrero de 1796), folio 127.

23. AHPB. PN. Martín Robredo. Legajo 6961 (15 de noviembre de 1720), folio 182. 
el escribano no lo precisa de manera categórica. Llevado este aserto a una manifiesta y virulenta impugnación de la ecuación sostenida, las armas de fuego -escopetas, trabucos, arcabuces, fusiles y carabinas- aparecidas en los inventarios estaban destinadas en su totalidad a la práctica cinegética, estas páginas no tienen justificación. A mi juicio, ello no es asumible. Descuellan, en especial, los inventarios de los clérigos. En ellos, y en un rutilante $29.4 \%$, se indica que las armas y sus complementos estaban orientados a dicho ejercicio -véase Cuadro 2-.

\begin{tabular}{|c|c|c|c|c|}
\hline CUADRO 2 & \multicolumn{4}{|c|}{ ARMAS LARGAS Y DE CAZA EN LOS INVENTARIOS DE BIENES } \\
\hline & TOTAL HOGARES & INVENTARIOS & CAZA & \\
\hline & CON ARMAS LARGAS & CON ARMAS & CONSIGNADA & $\%$ \\
\hline HILANDERAS & 1 & 1 & & \\
\hline LABRADORES & 15 & 15 & & \\
\hline ARTESANOS & 23 & 19 & 4 & 21 \\
\hline COMERCIANTES & 23 & 22 & 1 & 4.5 \\
\hline BURÓCRATAS & 41 & 39 & 2 & 5.1 \\
\hline SERVICIOS PÚBLICOS & 24 & 22 & 2 & 9.1 \\
\hline NOBLES RENTISTAS & 31 & 30 & 1 & 3.3 \\
\hline CLÉRIGOS & 17 & 12 & 5 & 41.7 \\
\hline MILITARES & 3 & 2 & 1 & 33.3 \\
\hline TOTAL BURGOS & 178 & 162 & 16 & 9.8 \\
\hline \% & 100 & 91 & 9 & \\
\hline Fuente documental: AHPB. PN. Múltiples Legajos. & & & \\
\hline
\end{tabular}

Los más acertados, a este respecto, fueron el escribano Rafael Antonio Pérez, quien inventarió en casa del panadero Bernardo Givofe «Una Escopeta para cazar», valorada en 180 reales $^{24}$ y los escribanos José Antonio Herrera, Francisco García de la Penilla y Gregorio Padrones. En el inventario post-mortem del maestro platero Juan Rodríguez Castro se señala la presencia de "Una Escopeta de Caza con fogón y marcas de oro en el Cañón, llave y guardamano y cantonera hecha de Ligón", tasada en 480 reales $^{25}$. García de la Penilla apuntó en el inventario de bienes del boticario José Martínez la presencia de «Una Escopeta con su grano de oro y demás trastos de Caza como son frasco de madera de el ayre y su zinto y bolsas", valorado todo ello en 240 reales $^{26}$. En el post-mortem del mesonero, calesero y labrador José Hidalgo, el escribano Padrones anotó «Una Escopeta larga de caza lisa y llana, [con] llave catalana” (60 reales) ${ }^{27}$.

24. AHPB. PN. Rafael Antonio Pérez. Legajo $7269 / 7$ (27 de febrero de 1782), sin foliar.

25. AHPB. PN. José Antonio Herrera. Legajo 7068/2 (7 de febrero de 1736), folio 253.

26. AHPB. PN. Francisco García de la Penilla. Legajo 6985/3 (10 de septiembre de 1731), folio 52.

27. AHPB. PN. Gregorio Padrones. Legajo 7136 (10 de marzo de 1764), folio 152. 
En las demás ocurrencias, inferimos la dedicación cinegética en función de los complementos que se detallan en los inventarios. El maestro armero Mateo Valderrama era propietario de cuatro escopetas (700 reales), "las dos de poca calidad y otras dos regulares» -tasadas en 180 reales- y de «Un Morral para Caza con cinturón, bolsa y frasco de lija» (40 reales) ${ }^{28}$. La "Escopeta corta con su gancho» (30 reales) del maestro platero Francisco García Gutiérrez tenía en «Un frasco de Caza con muelles de bronce, su cordón de lana y una Bolsa para perdigones» un complemento idóneo ${ }^{29}$. El mercader de paños y sedas Pedro Ramón Bernáldez de Velasco era propietario de dos escopetas, de "Un frasco y bolsas de caza" ( 8 reales) y de «tres arrobas y diez libras de Mostazilla y perdigones y doce libras de pólvora" (158 reales) ${ }^{30}$.

El escribano Diego Huidobro Garoña atesoraba, entre los enseres de su cultura material, dos escopetas (200 reales) y «Un frasco y Bolsas de Caza» (12 reales) ${ }^{31}$. El sobradero del Hospital del Rey Damián Antón era poseedor de "Un cinto de caza» (4 reales), un morral (10 reales), un frasco de pólvora (10 reales) y tres escopetas, tasadas en 240, 350 y 40 reales respectivamente ${ }^{32}$. El aristócrata y regidor perpetuo Bernardo Íñigo de Angulo era propietario de "Dos Cartucheras para Caza con cinto de ante» (30 reales), dos cuchillos de monte (37 reales), tres trabucos (120 reales) y cuatro escopetas (290 reales), entre las cuales sobresalía «Una Escopeta larga con mira y punto de plata", tasada en 120 reales $^{33}$.

Entre los clérigos descuella el comendador del Hospital del Rey Manuel Hoces Córdoba, poseedor de «Una bolsa de Caza, un frasco de madera del aire para lo mismo» (6 reales), un trabuco ( 47 reales) y dos escopetas $\left(74\right.$ reales) ${ }^{34}$. El capellán del Hospital de Barrantes Juan Pérez Ceballos, al parecer consumado cazador, era propietario de "Un frasco de caza con su cordón de seda» (12 reales), "Un frasco de caza con cuerno guarnecido en hierro grabado con su cordón de seda" (8 reales), «Una Cartuchera de ante de caza» (7 reales), 2 morrales con sus bolsas (16 reales), "Una bayoneta para Caza con su vaina» (8 reales), "Una Escopeta de Bustin Dui...» (540 reales) -citada anteriormente- y "Una Escopeta de Pedro Esteban con llave de Joseph Gómez, también con grano de oro» (220 reales), además de otros complementos $^{35}$. El canónigo catedralicio Luis Félix San Martín disponía de «Una Escopetta con su bolsa llena de todos trasttos de caza»(300 reales) ${ }^{36}$. A la postre,

28. AHPB. PN. Feliciano Medel de Prada. Legajo 7258/2 (17 de octubre de 1781), folio 235.

29. AHPB. PN. Jacinto del Río. Legajo 7149 (23 de septiembre de 1729), folios 68-69.

30. AHPB. JM. Juan Antonio Fernández Guilarte. Legajo 976 (12 de septiembre de 1739), folios 14 y 19.

31. AHPB. PN. Juan Antonio Fernández Guilarte. Legajo 7008 (7 de agosto de 1741), folio 593.

32. AHPB. PN. Félix Martín Antón. Legajo 8319 (25 de abril de 1785), folio 129.

33. AHPB. PN. Ángel Arnaiz. Legajo 7173 (22 de abril de 1776), folio 241.

34. AGP. Gaspar Tomé González. Legajo 52/11 (17 de mayo de 1753), folio 3.

35. ACCB. AMP. Legajo 133 (10 de enero de 1776), folio 560.

36. AHPB. PN. Agustín Hurtado de Saracho. Legajo 6938/1 (6 de abril de 1728), folio 124. 
el capiscol, dignidad y canónigo catedralicio Juan Francisco Guzmán Santos era probablemente un habitual cazador. Entre sus pertenencias destaca "Un frasco de Caza de madera del Aire con Guarniziones de Metal y cordones» (20 reales), un morral de lienzo con su red y "comporta de Christal» (8 reales), una cartuchera de ante con sus bolsas ( 5 reales), una bolsa de ante para munición ( 4 reales) y dos escopetas, una de ellas realmente admirable - «na Escopeta larga con el punto y fogón de oro»-, valorada en 600 reales $^{37}$.

Una afición desmedida por la práctica cinegética tenía, a pesar de sus problemas en la vista, el citado coronel de los Reales Ejércitos Miguel Antonio de la Torre, propietario de "Tres frascos, los dos de bufano y el otro de buez, para caça" (38 reales), «Una bolsa de caza de camucilla con sus muelles» (11 reales), «Un zinto con dos bolsas y su gancho para caza, sacatrapos, labador y martillo" (15 reales), complementos ideales para un trabuco (120 reales) y cinco escopetas, tasadas en 1.540 reales $^{38}$.

Ya sean 400 o 929 los inventarios de bienes, todos ellos han de ser tratados con las matizaciones oportunas sobre su validez, credibilidad y representatividad. Es, en suma, imprescindible sopesar, a través de un análisis crítico riguroso, la verosimilitud de la presencia de armas largas y de pertrechos para la práctica de la caza que se rastrean en los hogares burgaleses del Setecientos, con los notorios contrastes que se extraen de las diferentes categorías socioprofesionales, estamentos y niveles de fortuna existentes en la ciudad preindustrial castellana.

En la redacción de este trabajo son de singular importancia no solo la documentación histórica recopilada en los distintos "yacimientos" de información cuanto el acceso y reflexión efectuados en el acervo bibliográfico disponible sobre la caza, por una parte, y la cultura material, por otra, en el Antiguo Régimen y, en especial, en lo tocante al siglo XVIII.

Los 929 inventarios de bienes recopilados proceden, en su inmensa mayoría, del Archivo Histórico Provincial de Burgos (97.1\%), ya sea de la sección Protocolos Notariales (873 documentos, es decir, el $94 \%$ ) [AHPB. PN] o de Justicia Municipal (29 documentos, o sea, el $3.1 \%$ ) [AHPB. JM]. En segundo término, 11 inventarios han sido localizados en el Archivo Capitular de la Catedral de Burgos (1.2\%) [ACCB]. En tercera instancia, en el Archivo Municipal de Burgos se han recopilado 9 documentos (1\%) [AMB]. A la postre, en el Archivo General de Palacio (Madrid) se han hallado 4 inventarios (0.4\%) [AGP]. En el Archivo de la Diputación Provincial de Burgos se custodian 2 inventarios (0.2\%) [ADPB] y, en último término, en el Archivo Diocesano de Burgos se constata la presencia de un documento (0.1\%) [ADB]. Los escribanos que elaboraron los inventarios localizados en los archivos citados eran, a la postre, los del número del Ayuntamiento, los del Cabildo Catedral o quienes

37. AHPB. JM. Alonso Melo Peña. Legajo 987 (16 de septiembre de 1778), folios 11-12 y 24.

38. AHPB. JM. Juan Antonio Fernández Guilarte. Legajo 976 (7 de mayo de 1751), folios 19 y 30. 
desarrollaban sus quehaceres profesionales en el Hospital del Rey y en el Real Monasterio de Las Huelgas en el devenir del siglo XVIII.

Sobre las prácticas cinegéticas en el Setecientos descuellan múltiples aportaciones. Se ha efectuado un rastreo, lo más intenso posible, en el acervo bibliográfico disponible, herramienta esencial en el amueblamiento de una reconstrucción científica creíble del pretérito. En España, destacan, citadas sin un ánimo exhaustivo ni pretendiendo hilvanar un estado de la cuestión, las reflexiones de -véase 6. Bibliografía- Caro López, Ladero Quesada, Sánchez González, López Ontiveros, Izquierdo Martín y Sánchez León, Sanz de la Higuera, Inglada Atarés, Revilla, Bustos Torres, Hernando Sánchez o Cuesta Nieto. Desde la perspectiva internacional, descuellan las aportaciones francesas, alemanas, británicas e italianas. Desde la óptica francesa, véanse las propuestas de Lagadec, Brunet, Salvadori, Moulin, Cattin, Corvol, Beck, Luzco o Cadet. En Alemania, son incuestionables, e imprescindibles, las obras de Rösener, Knoll, Schwenk y Hepp. En Gran Bretaña, Thompson, Itzkowitz, Washburn, Knoll y Arditi. En el ámbito italiano, de Nicoló, Torriti, Ciuffoletti, Galloni o Dani. También son muy significativas las propuestas de Sosa Mayor ${ }^{39}$ en lo tocante a las atribuladas problemáticas de la nobleza en sus prácticas en la "caza vedada", su distinción, los posibles pecadores en ese terreno y las presumibles restituciones a que estaban obligados en caso de malas praxis.

Estas páginas se enmarcan en el contexto de la reconstrucción de la cultura material en el siglo XVIII. De entre las múltiples aportaciones, descuellan -véase 6. Bibliografía- los trabajos de García Fernández, Ramos Palencia, Sobrado Correa, Bartolomé Bartolomé, Álvarez Santaló y García-Baquero González, Madureira, Shammas, Weatherill, Baulant, Schuurman y Servais, Waro-Desjardins, Sarti o Ago.

\section{CAZA, ¿NECESIDAD U OCIO?}

La presencia de armas de fuego largas -escopetas, arcabuces, trabucos, fusiles y carabinas- en los inventarios de bienes de los hogares burgaleses del XVIII nos lleva a plantearnos si dicha aparición en los interiores domésticos era una mera casualidad o, circunstancia que parece más probable y asumible, tal armamento era susceptible de ser usufructuado en la realización de prácticas cinegéticas por parte de sus propietarios. No todos, empero, recurrían a esas armas por las mismas razones. En esencia, tres fueron los motivos que, a mi juicio, justifican, a título explicativo, la aparición entre sus pertrechos de dicho armamento.

No hemos de olvidar, por supuesto, que tales armas podían ser también utilizadas, eventualmente, para la protección personal y del hogar o como pertrecho bélico en caso de conflicto armado si eventualmente fuera necesario. Empero,

39. SOSA MAYOR, Igor. El noble atribulado. Nobleza y teología moral en la Castilla moderna (1559-1650). Madrid: Marcial Pons, 2018, pp. 345-366. 
parece razonable pensar que lo habitual era su instrumentalización como herramienta cinegética, fuera para incrementar los volúmenes de comida disponibles en las mesas -léase labradores y artesanos-; practicar un ocio «ecológico" y exhibicionista -en especial, comerciantes, tenderos, burócratas, profesionales de los servicios públicos y eclesiásticos,- o, además de lo anterior, ejercitarse en prácticas de adiestramiento y entrenamiento militar, apropiadas, y aun exigibles, para el estamento noble -véase la nobleza rentista y aristócrata y los mandos militares-. "La chasse c'est le moyen de rompre la monotonie de la vie quotidienne [et] un exercice violent que l'on croit salutaire à la santé „40, actividad practicada por aristócratas y paupérrimos según sus particulares necesidades.

Sánchez González nos alerta de posibles presentismos que, llevados por un mercantilismo agresivo y por diferentes interpretaciones antropológicas, sujetas a la mentalidad vigente en cada época, han relacionado la actividad cinegética con el ocio y el disfrutar "el tiempo alegremente ${ }^{41}$. En esencia, plantea que para la nobleza, enraizada en una tradición medieval de espíritu guerrero, la caza era un quehacer consustancial a su existencia y más que una forma de esparcimiento la caza era un símbolo distintivo de poder, una tarea exclusiva y excluyente reservada a una minoría privilegiada. Para las clases populares la actividad cinegética era una forma de supervivencia, siempre en precario, casi siempre al filo de la ilegalidad, una fuente de recursos complementarios que ayudaba a superar sus dificultades existenciales ${ }^{42}$.

Como señala muy acertadamente, a mi entender, Sosa Mayor ${ }^{43}$,

En general, el ámbito cinegético es en la Edad Moderna un ámbito socialmente conflictivo, toda vez que en él se dan cita aspectos muy dispares e intereses contrapuestos: era ámbito de distinción social y fuente de recursos vitales relevantes, atañía a las necesidades económicas de las poblaciones y a los equilibrios ecológicos, y se veía regulado por disposiciones legales, relaciones políticas de fuerza y [...], de forma directa e indirecta, cuestiones morales.

En efecto, entre los menos afortunados, y en muchos casos más paupérimos, es decir, entre las categorías socioprofesionales abocadas al trabajo productivo primario o secundario, labradores, hortelanos y artesanos, la posesión de armas susceptibles de ser empleadas en la caza estaba relacionada directamente con la aprehensión de animales que complementaran los escasos volúmenes de dieta que podían obtenerse con sus quehaceres laborales. Tenían pocas armas, de muy baja

40. «Chasses royales au XVIIIe siécle». La France Agricole, 2902, 2001.

41. SÁnchez GonZÁlez, Ramón. La caza en Toledo y sus montes durante el Antiguo Régimen. Ciudad Real: Universidad de Castilla-La Mancha, 2003, p. 8.

42. SÁNCHEZ GONZÁlez Ramón. La caza..., p. 8, e IZQUiERdo MARTín, Jesús y SÁNCHEZ LEón, Pablo. "Racionalidad sin utilitarismo: La caza y sus conflictos en El Escorial durante el Antiguo Régimen». Historia Agraria, 2001, 24, pp. 125-126.

43. SOSA MAYOR, Igor. El noble atribulado..., p. 346. 
calidad y precio, baratas y rudimentarias, cuando no viejas y obsoletas, y respondían a un perfil puramente instrumental. La "caza menor» era una actividad económica, por cuanto representaba una fuente de ingresos «que permitía equilibrar el balance alimenticio de la familia» y obtener otros recursos económicos. Quienes disponían de un arma de cañón largo lo que pretendían, en esencia, era salir a los campos a cobrarse alguna pieza cárnica -perdiz, conejo, liebre...- que poder llevarse a la boca no por afición u ocio, sino por una necesidad básica de carácter alimenticio ${ }^{44}$.

En un segundo estadio, hemos de considerar aquellas categorías socioprofesionales que hacían de la práctica cinegética una actividad relacionada con el ocio, con la afición por dedicar cierto tiempo a ejercitarse físicamente en un ambiente natural, sentir el dominio del ser humano sobre las bestias del campo y aportar, también, a sus mesas carnes de gran frescura y calidad, fórmulas de emulación y parangón, en la medida de lo posible, por supuesto, con las cacerías reales y de la aristocracia de mayor alcurnia. La práctica de la caza era un deporte con matices e ideología burguesa. Las tasaciones y número de piezas de sus armas de cañón largo nos aproximan a hogares en que, además de lo eminentemente funcional, prima, sobre todo, la prestancia de las armas adquiridas, pertrechos y complementos de caza que se exhiben como instrumentos de contraste entre personas y hogares, en el seno de una cultura de las apariencias en la que lo substancial era disponer de vestimentas, carruajes, adornos personales o armas de caza de la mayor calidad, origen geográfico selecto y materias primas de alcurnia posibles. Aunque vivían lejos de la Corte, el colgarse a la espalda la escopeta y pertrechar sus cinturas con cartucheras, frascos para pólvora, bayonetas y cuchillos de monte era una fórmula de emulación con respecto a la realeza, con la aristocracia titulada, circunstancia que daba a sus existencias no solo la sensación, sino, en especial, la certeza de ser los más importantes y poderosos de la sociedad que les rodeaba, en la que estaban inmersos aunque, por supuesto, se ubicaban en la parte más encumbrada de la pirámide socioeconómica. Habían nacido para vivir en la comodidad, en el confort, para mandar y ser obedecidos y para disfrutar de una existencia lo menos aburrida y grosera posible. Salir de caza era una diversión muy exclusiva, exótica, selecta, diferencial, que muy pocos podían permitirse. "La caza -enfatiza Sosa Mayor- ${ }^{45}$ se hallaba [...] inmersa en profundos cambios de sus prácticas y definiciones, lo que imprime mayor complejidad a su evolución en la Edad Moderna: paulatina permisión del uso de armas de fuego, mayor duración temporal de las cacerías, creación de cotos de caza con un número cada vez más alto de piezas, etc.».

44. Nos hallamos ante un "gran número de personas, poseedoras de pedazos de tierra demasiado pequeños, [que] alternaban el cultivo con la caza, la pesca, el transporte o el artesanado, sin que pueda decidirse si la agricultura era para ellas ocupación principal o secundaria y accesoria». DOMínGUEz ORTIZ, Antonio. Sociedad y Estado en el siglo XVIII español. Barcelona: Ariel, 1990, pp. 402-304.

45. SOSA MAYOR, Igor. El noble atribulado..., p. 347. 
En última instancia, como se ha anunciado anteriormente, la nobleza rentista, terrateniente y dirigente del Concejo y los militares -y quizá también alguno de los más importantes burócratas- tenían entre sus enseres domésticos escopetas, trabucos, carabinas o fusiles, como una seña de identidad indisolublemente ligada con su idiosincrasia estamental. Aunque, en la práctica, se había producido un alejamiento progresivo de la actividad armada, en la cotidianeidad o en la excepcionalidad de las guerras, de los duelos o de las competiciones lúdicas, los privilegiados aún persistían en una evanescente, quizá fantasmagórica, relación épica con el manejo de armas, ya fueran blancas o de fuego, como recuerdo fosilizado, un tanto etéreo y meramente recurrente, de épocas en que la nobleza estaba indisolublemente llamada al auxilio armado a la monarquía. La "caza mayor", "montería" o "venatoria", constituía no solo un esparcimiento cuanto, sobre todo, un adiestramiento y preparación física y moral, como se expone en los Libros de Montería. Las grandes dimensiones de los animales -ciervos, osos y jabalíes, principalmente- exigían prácticas de persecución, acoso y muerte, sobre terrenos agrestes y con una dotación animal -caballos, perros, halcones...- y técnica a la que muy pocos tenían acceso ${ }^{46}$. El privilegio de la caza era descrito como «uno de los elementos legitimadores del discurso de la nobleza basada en la raza y la sangre. La caza permitía mostrar valor, fortaleza y autoridad, ingredientes todos ellos que van configurando el habitus nobiliario del grupo" ${ }^{47}$.

La caza y las conductas económicas, en resumen, dependen del grupo social que las practica, señalan Izquierdo Martín y Sánchez León (2001: 124). En concreto, la caza no es reducible a una única racionalidad-instrumental, como la defiende la microeconomía neoclásica-, sino que obedece muy en primer término también a otros cánones de racionalidad esencialmente expresivos. La caza era un quehacer a través del cual los nobles y las demás categorías socioprofesionales expresaban su pertenencia a sus respectivas comunidades de identidad. "La caza era una actividad tan valorada y necesaria por la mayor parte de la población que oponerse a ella no era fácilı ${ }^{48}$.

46. En los inventarios de bienes de los burgaleses del XVIII con armas de caza no aparecen, empero, ninguno de ellos. La excepción proviene del clérigo Bernáldez de Velasco, poseedor de «dos urones biejos", tasados en 40 reales de vellón. AHPB. PN. Domingo Ibáñez Varona. Legajo 6985/2 (23 de septiembre de 1728), folio 524 .

47. SOSA MAYOR, Igor. El noble atribulado..., p. 347; JuOANNA, Arlette. «Die Legitimierung des Adels und die Erhebung in den Adelsstand in Frankreich (16.- 18. Jahrhundert)». En Schulze, Winfried (ed.). Ständische Gesellschaft und soziale Mobilität. Múnich: Walter de Gruyter, 1988, pp. 167-171; RÖSENER, Werner (ed.). Jagd und böfische Kultur im Mittelalter. Göttingen: Vandenhoek \& Ruprecht, 1997, pp. 23-24, y WinkELBAUR, Thomas. Fürst und Fürstendiener: Gundakervon Lichtenstein, ein österreichischer Aristokrat des konfessionellen Zeitalters. Viena: Oldenbourg, 1999, pp. 454-455.

48. SOSA MAYOR, Igor. El noble atribulado..., p. 350 
2.1. ¿Con qué armas de fuego largas nos topamos en los inventarios de bienes?

El rastreo intensivo efectuado en los 929 inventarios de bienes recopilados para el Burgos del Setecientos ha deparado la aparición de 201 armas de fuego largas. No todas eran de la misma categoría ni calidad -véanse Cuadro 3 y Cuadro 4-. El 73.2 \% era escopetas -con dos de promedio y 199 reales de vellón de media por hogar-. Las escopetas aparecen, en especial, entre los burócratas -suponen el $22.4 \%$ de las ocurrencias- y los nobles rentistas -con el $17.1 \%$ y dos armas y 435 reales de promedio. En las demás categorías socioprofesionales, los guarismos son bastante menos significativos-. En segundo término, los trabucos -que suponen el $13.9 \%$ de las armas largas localizadas, con, de promedio, dos armas y 69 reales de tasación-. Los trabucos aparecen, también, sobre todo, en las casas de los burócratas $-25.1 \%$, con un trabuco de promedio y 52 reales de tasación- y en los hogares de los nobles rentistas $-21.4 \%$, con dos armas y 172 reales, de promedio-. En las otras categorías socioprofesionales se detectan situaciones similares a lo anteriormente señalado.

\begin{tabular}{|c|c|c|c|c|}
\hline CUADRO 3 & \multicolumn{4}{|c|}{ ARMAS DE CAZA EN EL XVIII BURGALÉS } \\
\hline & & & PROMEDIO & PROMEDIO \\
\hline & HOGARES & $\%$ & N. ${ }^{\circ}$ ARMAS & TASACIÓN (1) \\
\hline ESCOPETAS & 147 & 73.2 & 2 & 199 \\
\hline TRABUCOS & 28 & 13.9 & 2 & 69 \\
\hline ARCABUCES & 11 & 5.5 & 2 & 89 \\
\hline CARABINAS & 10 & 4.9 & 1 & 112 \\
\hline FUSILES & 5 & 2.5 & 2 & 57 \\
\hline TOTAL & 201 & 100 & 2 & 200 \\
\hline (1) En reales de vellón & & & \\
\hline Fuente documental: AHPB. PN. Múltiples Legajos. & \\
\hline
\end{tabular}

El arcabuz, con un $5.5 \%$, es la tercera arma en cuestión -dos arcabuces y 89 reales, de promedio-. Eran los comerciantes quienes más se decantaban por ellos -sucede en el 27.2 \% de sus ocurrencias-, con los nobles rentistas y los clérigos en segundo término $-18.2 \%$ de los arcabuces localizados, respectivamente-. Nobles y eclesiásticos disponían, de promedio, de un arcabuz, tasado en 105 y 130 reales, de promedio, respectivamente. La carabina supone el $4.9 \%$ de las armas larga de fuego localizadas. Los comerciantes y los nobles rentistas, con el $30 \%$ de ellas, respectivamente, fueron quienes osaron incorporarlas a sus acervos cinegéticos, seguidos por los burócratas -20\%-. En última instancia, el fusil únicamente supone el $2.5 \%$ de las armas recopiladas -con un promedio de dos por hogar y 57 reales de tasación media-. Los nobles rentistas eran propietarios del $40 \%$ de ellos -con dos armas y 82 reales, de promedio-. Los comerciantes, 
los burócratas y los profesionales de los servicios públicos se repartían, por igual, al $20 \%$, el porcentaje restante.

\begin{tabular}{|c|c|c|c|c|}
\hline CUADRO 4 & \multicolumn{4}{|c|}{ ARMAS DE CAZA EN LOS HOGARES } \\
\hline & & \multicolumn{2}{|c|}{ ESCOPETAS } & \\
\hline & & & PROMEDIO & PROMEDIO \\
\hline & HOGARES & $\%$ & N. ${ }^{\circ}$ ARMAS & TASACIÓN (1) \\
\hline HILANDERAS & 1 & 0.7 & 1 & 8 \\
\hline LABRADORES & 14 & 9.5 & 1 & 29 \\
\hline ARTESANOS & 21 & 14.3 & 1 & 124 \\
\hline COMERCIANTES & 16 & 10.9 & 2 & 112 \\
\hline BURÓCRATAS & 33 & 22.4 & 1.5 & 144 \\
\hline SERVICIOS PÚBLICOS & 19 & 12.9 & 1.5 & 101 \\
\hline NOBLES RENTISTAS & 25 & 17.1 & 2 & 435 \\
\hline CLÉRIGOS & 15 & 10.2 & 4 & 214 \\
\hline MLITARES & 3 & 2 & 3 & 1.217 \\
\hline \multirow[t]{2}{*}{ TOTAL BURGOS } & 147 & 100 & 2 & 199 \\
\hline & & \multicolumn{2}{|c|}{ TRABUCOS } & \\
\hline \multicolumn{5}{|l|}{ HILANDERAS } \\
\hline LABRADORES & 2 & 7.1 & 1 & 30 \\
\hline ARTESANOS & 1 & 3.6 & 1 & 40 \\
\hline COMERCIANTES & 5 & 17.8 & 1 & 32 \\
\hline BURÓCRATAS & 7 & 25.1 & 1 & 52 \\
\hline SERVICIOS PÚBLICOS & 5 & 17.8 & 1 & 47 \\
\hline NOBLES RENTISTAS & 6 & 21.4 & 2 & 172 \\
\hline CLÉRIGOS & 1 & 3.6 & 1 & 47 \\
\hline MLLITARES & 1 & 3.6 & 1 & 120 \\
\hline \multirow[t]{2}{*}{ TOTAL BURGOS } & 28 & 100 & 2 & 69 \\
\hline & & \multicolumn{2}{|c|}{ ARCABUCES } & \\
\hline \multicolumn{5}{|l|}{ HILANDERAS } \\
\hline LABRADORES & 1 & 9.1 & 1 & 30 \\
\hline ARTESANOS & 1 & 9.1 & 2 & 240 \\
\hline COMERCIANTES & 3 & 27.3 & 2 & 58 \\
\hline BURÓCRATAS & 1 & 9.1 & 1 & 12 \\
\hline SERVICIOS PÚBLICOS & 1 & 9.1 & 2 & 56 \\
\hline NOBLES RENTISTAS & 2 & 18.2 & 1 & 105 \\
\hline CLÉRIGOS & 2 & 18.2 & 1 & 130 \\
\hline \multicolumn{5}{|l|}{ MLITARES } \\
\hline \multirow[t]{2}{*}{ TOTAL BURGOS } & 11 & 100 & 2 & 89 \\
\hline & & \multicolumn{2}{|c|}{ CARABINAS } & \\
\hline \multicolumn{5}{|l|}{ HILANDERAS } \\
\hline \multicolumn{5}{|l|}{ LABRADORES } \\
\hline ARTESANOS & 1 & 10 & 3 & 880 \\
\hline COMERCIANTES & 3 & 30 & 1 & 47 \\
\hline BURÓCRATAS & 2 & 20 & 1 & 60 \\
\hline SERVICIOS PÚBLICOS & 1 & 10 & 1 & 360 \\
\hline NOBLES RENTISTAS & 3 & 30 & 2 & 134 \\
\hline \multicolumn{5}{|l|}{ CLÉRIGOS } \\
\hline \multicolumn{5}{|l|}{ MILITARES } \\
\hline \multirow[t]{2}{*}{ TOTAL BURGOS } & 10 & 100 & 1 & 112 \\
\hline & & \multicolumn{2}{|c|}{ FUSILES } & \\
\hline HILANDERAS & & & & \\
\hline LABRADORES & & & & \\
\hline ARTESANOS & & & & \\
\hline COMERCIANTES & 1 & 20 & 2 & 50 \\
\hline BURÓCRATAS & 1 & 20 & 1 & 30 \\
\hline SERVICIOS PÚBLICOS & 1 & 20 & 1 & 40 \\
\hline NOBLES RENTISTAS & 2 & 40 & 2 & 82 \\
\hline CLÉRIGOS & & & & \\
\hline MILITARES & & & & \\
\hline TOTAL BURGOS & 5 & 100 & 2 & 57 \\
\hline (1) En reales de vellón. & & & & \\
\hline Fuente documental: AHP & DN. Múltiples & jajos. & & \\
\hline
\end{tabular}




\section{2. ¿En qué hogares aparecen en el Setecientos armas de caza?}

En muchas viviendas nos topamos, al hilo de las anotaciones en los inventarios, con armas "blancas» -espadas, espadines, sables, alfanjes, dagas, puñales...y con armas de fuego cortas - pistolas-, caracterizadas por un marcado carácter funcional o entretenidas por un mero exhibicionismo personal, en el seno de una sociedad dada a la cultura de las apariencias o, incluso, como recordatorio de épicos pretéritos combatientes. Además, y suele ser simultáneo, los escribanos anotaron, y tasaron, armas de fuego de grandes dimensiones -escopetas, trabucos, arcabuces, fusiles y carabinas- susceptibles, como hemos señalado, de ser utilizadas por sus propietarios como armas de caza, en los quehaceres propios de prácticas cinegéticas circunstanciales. No sabemos cuándo eran disparadas, pero su tenencia pronostica su utilidad manifiesta.

\begin{tabular}{|c|c|c|c|c|c|c|}
\hline \multirow[t]{3}{*}{ CUADRO 5} & \multicolumn{6}{|c|}{ ARMAS DE CAZA EN LOS HOGARES DEL XVIII BURGALÉS } \\
\hline & \multicolumn{3}{|c|}{929 INVENTARIOS } & \multicolumn{3}{|c|}{400 INVENTARIOS } \\
\hline & & HOGARES & & & HOGARES & \\
\hline & HOGARES & CON ARMAS & $\%$ & HOGARES & CON ARMAS & $\%$ \\
\hline HILANDERAS & 48 & 1 & 2.1 & 19 & 1 & 5.3 \\
\hline JORNALEROS & 29 & 0 & 0 & 8 & 0 & 0 \\
\hline LABRADORES & 142 & 15 & 10.5 & 46 & 4 & 8.7 \\
\hline ARTESANOS & 176 & 23 & 13.1 & 54 & 5 & 9.2 \\
\hline COMERCIANTES & 93 & 23 & 24.7 & 39 & 10 & 25.6 \\
\hline BURÓCRATAS & 144 & 41 & 28.5 & 76 & 24 & 31.6 \\
\hline SERVICIOS PÚBLICOS & 100 & 24 & 24 & 49 & 11 & 22.4 \\
\hline NOBLES RENTISTAS & 92 & 31 & 33.7 & 33 & 16 & 48.5 \\
\hline CLÉRIGOS & 91 & 17 & 18.7 & 67 & 12 & 17.9 \\
\hline MILITARES & 14 & 3 & 21.4 & 9 & 3 & 33.3 \\
\hline TOTAL BURGOS & 929 & 178 & 19.2 & 400 & 86 & 21.5 \\
\hline Fuente documental: $A$ & AHPB. PN. ML & últiples Legajos & & & & \\
\hline
\end{tabular}

Desde una perspectiva general, en el Burgos del Setecientos detectamos la presencia de armas largas -véase Cuadro 5- en el entorno del $20 \%$ de los hogares $-19.2 \%$ si lo consideramos a través de la recopilación de 900 inventarios y $21.5 \%$ con el tratamiento de 400 documentos-. De manera genérica, y con contundencia y verosimilitud, se puede afirmar que en uno de cada cinco hogares burgaleses se disponía de armamento susceptible de ser empleado en prácticas cinegéticas, si bien no en todas las categorías socioprofesionales ni en los distintos estamentos o niveles de fortuna nos topamos con guarismos similares. En el Antiguo Régimen, y en especial en el siglo XVIII, la caza era aún abundante, de manera sintomática en el caso de las perdices, pero, en general, existían pocas armas de fuego en manos de los vecinos, sea por razones de índole económica y patrimonial -niveles de renta y fortuna- o por la disponibilidad, o no, de tiempo para ejercitarse en tales quehaceres. Quizá los más paupérrimos recurrían a artimañas no detectables a través de los inventarios. 
FRANCISCO SANZ DE LA HIGUERA

ENTRE EL OCIO Y LA NECESIDAD: LA PRÁCTICA DE LA CAZA EN EL BURGOS DEL SETECIENTOS

\begin{tabular}{|c|c|c|c|c|c|c|}
\hline CUADRO 6 & \multicolumn{6}{|c|}{ ARMAS DE CAZA EN LOS HOGARES BURGALESES DEL SETECIENTOS } \\
\hline & HOGARES & & PROMEDIO & PROMEDIO & NIVEL DE FORTUNA (1) \\
\hline & CON ARMAS & $\%$ & N. ${ }^{\circ}$ ARMAS & TASACIÓN (1) & CON ARMAS & SIN ARMAS \\
\hline HILANDERAS & 1 & 2.1 & 1 & 8 & 5.018 & 2.153 \\
\hline LABRADORES & 15 & 10.5 & 1 & 34 & 30.652 & 11.065 \\
\hline ARTESANOS & 23 & 13.1 & 1 & 142 & 51.777 & 14.811 \\
\hline COMERCIANTES & 23 & 24.7 & 2 & 105 & 161.032 & 83.294 \\
\hline BURÓCRATAS & 41 & 28.5 & 2 & 135 & 158.898 & 81.547 \\
\hline SERVICIOS PÚBLICOS & 24 & 24 & 2 & 112 & 34.223 & 15.604 \\
\hline NOBLES RENTISTAS & 31 & 33.7 & 2 & 431 & 207.560 & 90.091 \\
\hline CLÉRIGOS & 17 & 18.7 & 2 & 231 & 31.567 & 54.633 \\
\hline MILITARES & 3 & 21.4 & 4 & 1.285 & 517.406 & 82.322 \\
\hline TOTAL BURGOS & 178 & 19.2 & 2 & 200 & 119.207 & 39.519 \\
\hline (1) En reales de vellón. & & & & & & \\
\hline Fuente documental: AHPB. PN. Múltiples Legajos. & & & \\
\hline
\end{tabular}

¿En qué categorías socioprofesionales se detecta su aparición documental? Los porcentajes que destilan de la documentación recopilada -véase Cuadro 6- son, a mi entender, modélicos, cuando no paradigmáticos. Las categorías socioprofesionales más paupérrimas, más populares y endebles desde la óptica económica no poseían, en ningún caso, armas en más del $15 \%$ de los hogares. Las categorías que conformaban la sociedad burgalesa intermedia, las "clases medias» del entramado socioeconómico y profesional, disponían de armamento de caza en índices del 15 al $30 \%$. A la postre, la nobleza rentista y dirigente del Concejo, la aristocracia urbana burgalesa preñada de títulos y rentas de mayorazgos, se situaba, en este sesgo, por encima del $30 \%$ de hogares dotados de armas de caza. La sociedad borbónica no estaba exenta de una insistente política de reglamentación de la caza y de la pesca. Además de un control riguroso de las actividades tradicionales, se pretendía, sobre todo, potenciar ideologías, ya fuera, por una parte, para la defensa de una sociedad jerarquizada y con una mentalidad aristocrática -lastrada aún por fuertes pervivencias del pretérito, con una continuidad sustancial devenida del siglo Xvir y su mentalidad austracista- y, por otra, posibilitar la eclosión de ideologías más innovadoras y progresistas, más propias de las categorías socioeconómicas de los despachos, de las lonjas, de las viviendas del individualismo y la visión de futuro. Todos ellos podían estar aquejados de problemas de conciencia, pero, fuera por deporte y ocio o fuera por necesidad, un segmento notable de la sociedad urbana burgalesa se había decantado ya por introducirse por la senda de la práctica de la caza ${ }^{49}$.

49. Es preciso, cuando sea posible, efectuar un contraste con la aparición de armas largas en el siglo XVII y en el siglo XIX para poder solventar una hipótesis inquietante: ¿La presencia de escopetas, trabucos, arcabuces, fusiles y carabinas fue mayor en el Setecientos que en las centurias anterior y posterior? 
Por lo que respecta al primer umbral -menos del $15 \%-$, se alinean en él, en primera instancia, los jornaleros del campo -sin armas en ninguna de las opciones posibles, con 900 o con 400 inventarios-. La absoluta carencia de armas de fuego está en la línea de ser hogares "que tenían poco de casi todo»" En segundo término -véase Cuadro 6-, las categorías socioprofesionales en las que se presume que la disponibilidad de armas largas tiene como objetivo esencial la adquisición, por pura necesidad, de alguna pieza de caza con la que mejorar, en la medida de lo posible, sus viandas, su deficiente alimentación, si bien no se descarta la posibilidad de que, en algunos casos puntuales, también exista un marcado sesgo "deportivo", de ocio, en especial en aquellos hogares en los que las escopetas presentan un elevado coste económico y una manifiesta calidad fabril. Para las hilanderas y pobres de solemnidad, descubrimos la presencia de algún arma larga en el $2.1 \%$ de hogares -con 400 inventarios el porcentaje fue del $5.3 \%$-. El único hogar en que se documenta un arma susceptible de ser empleada en la caza es el de Ana M. ${ }^{a}$ Martínez Huertos, viuda del burócrata Juan Añejo. Se trata de una hidalga, propietaria, quizá a su pesar, de «Una Escopeta con su llave», tasada en 8 reales $^{51}$, una cantidad, sin duda, irrisoria, si la comparamos con los promedios hallados para las demás categorías socioprofesionales -véase Cuadro 6-. Es probable que su situación fuera más sostenible que la de María Simancas, quien recurría, para su sostenimiento, a la venta de pertrechos "por remediar nezesidades [...] para vestirme yo y vestir a mi hija, porque mis Hermanos no me han dado más que la comida ${ }^{52}$.

Los labradores y hortelanos se postulan, en tercer lugar, con un 10,5\% de hogares con tal armamento si consideramos desde la perspectiva de los 929 inventarios -con 400 suponía un 8.7 \%-. El promedio del número de piezas, una/hogar, y de la tasación de sus armas largas, 34 reales, describen, también, un escenario mediocre. El arma de mayor calidad era propiedad de Pedro Carrera, una escopeta valorada en 40 reales $^{53}$. Para los artesanos, la posesión de armas de caza no era, tampoco, un aspecto excesivamente significativo. Se localizan escopetas u otras armas susceptibles de ser usadas en la práctica cinegética en el $13.1 \%$ de los hogares $^{54}$. Se decantaban más por la posesión de espadas, espadines, cuchillos largos de camino, sables, dagas y pistolas. Las escopetas u otras armas de cañón largo

50. Moreno Claverías, Belén. «Pautas de consumo y diferenciación social en El Penedés a fines del siglo XVII. Una propuesta metodológica a partir de inventarios sin valoraciones monetarias». En TORRAS, Jaume y Yun, Bartolomé (eds.). El consumo en la España pre-industrial, Revista de Historia Económica, 2003, n. ${ }^{\circ}$ extraordinario, pp. 230-232, y BRAUDEL, Fernand. Civilización material, economía y capitalismo. Siglos XV-XVIII. 1. Las estructuras de lo cotidiano. Madrid: Alianza Editorial, 1984, pp. 238-240.

51. AHPB. PN. Bernardo Alonso Illera. Legajo 7188 (19 de marzo de 1757), folio 15.

52. ADPB. Catastro de Ensenada. Respuestas Particulares. Libro 345, folio 1.043.

53. AHPB. PN. Gaspar Tomé González. Legajo 8309 (27 de enero de 1753), folio 242.

54. Con el cómputo devenido de 900 inventarios. Con 400, 9,2\%. 
apenas representaban un $18 \%$ del valor de sus armas. Su calidad tampoco era muy elevada, con un promedio de 142 reales y un arma por hogar. Es interesante la dotación de que era propietario el maestro armero Mateo Valderrama. En su inventario post-mortem, el escribano describió «Quatro Escopetas, las dos de poca calidad y otras dos regulares", tasadas en 700 reales, "Dos cañones nuebos y varias llaves usadas» (180 reales) y «Un Morral para caza con cinturón, bolsa y frasco de lija» (40 reales) ${ }^{55}$. Es significativa "Una Escopeta de Caza, con fogón y marcas de oro en el Cañón, llave y guardamano y cantonera, hecha de Ligón", evaluada en 480 reales de vellón ${ }^{56}$. Descuella, también, el panadero de origen francés Bernardo Givofe, poseedor de «Una Escupeta para cazar», tasada en 180 reales ${ }^{57}$. El maestro curtidor y tanador Felipe González disponía de "Dos Arcabuces Con sus llaves, el uno de cinco quartas y el otro de seis quartas escasas" (240 reales) ${ }^{58}$.

En un segundo escalón -véase Cuadro 6- se alineaban aquellas categorías socioprofesionales para las que podemos presumir de la existencia de prácticas cinegéticas orientadas hacia el ocio. En ellas, la presencia de armas largas -escopetas, trabucos, arcabuces, fusiles o carabinas- se coloca entre el 15 y el $30 \%$ de los hogares recopilados. Aunque en sus mesas se dispusieran, cocinadas, las piezas que se cobraban con sus armas de caza ${ }^{59}$, la explicación al hecho de que nos topemos con armas de tales características era su uso lúdico, el echarse al campo o al monte con intención "deportiva" -valga el presentismo-. Los clérigos, con el $18.7 \%$ de los hogares recopilados provistos de armas de fuego -con 400 inventarios supuso el $17.9 \%$-, disponían, de promedio, de dos armas, tasadas en 231 reales. Sobresale, con mucho, el capiscol catedralicio, Juan Francisco Guzmán Santos, provisto de dos escopetas, valoradas en 900 reales, y múltiples complementos ${ }^{60}$. En segunda instancia, el capellán del Hospital de Barrantes Juan Pérez Ceballos, también poseedor de dos escopetas y abundantes pertrechos auxiliares ${ }^{61}$. Encontramos armas de caza en el 21,4\% de los hogares de militares -fue el 33,3\% con 400 documentos-. Su promedio de armas, cuatro, y la media de la tasación, 1.285 reales de vellón, son, por razones obvias, los más significativos de entre los hogares burgaleses. El mejor dotado era el citado coronel de Infantería Miguel Antonio de la Torre, propietario de cinco escopetas, tasadas en 1.540 reales $^{62}$, aunque el marqués de Lorca, Francisco

55. AHPB. PN. Feliciano Medel Prada. Legajo 7258/2 (17 de octubre de 1781), folio 235.

56. AHPB. PN. José Antonio Herrera. Legajo 7068/2 (7 de febrero de 1736), folio 253.

57. AHPB. PN. Rafael Antonio Pérez. Legajo 7269/7 (27 de febrero de 1782), sin foliar.

58. AHPB. PN. Lázaro Santamaría. Legajo 6870 ( 9 de abril de 1715), folio 165.

59. PÉREZ SAMPER, M. ${ }^{a}$ Ángeles. Mesas y cocinas en la España del siglo XVIII. Gijón: Ediciones Trea, 2011.

60. AHPB. JM. Alonso Melo Peña. Legajo 987 (16 de septiembre de 1778), folios 11-12 y 24.

61. ACCB. AMP. Legajo 133 (10 de enero de 1776), folio 560. Véase igualmente al canónigo catedralicio Severino Vedía Quevedo. AHPB. PN. Juan Antonio Fernández Guilarte. Legajo 6990 (6 de mayo de 1720), folio 227.

62. «Una Escopeta de Esquivel, el Mro que fue del Rey, con el grano i marcas de oro, en veinte doblones» (1.200 reales de vellón), «Una escopeta de Simón» (60 reales), "Una Escopeta de Mros 
Castro Torre Cárdenas, capitán de infantería y gentilhombre de cámara de Su Majestad, no le desmerecía en absoluto ${ }^{63}$.

Los profesionales de los servicios públicos, en especial médicos y boticarios, atesoraban armas de caza en el $24 \%$ de sus hogares -con 400 inventarios, el $22.4 \%$-, con un promedio de dos armas y 112 reales -compárese con lo hallado para nobles rentistas y militares-. Descuellan el médico Manuel Balmaseda, poseedor de dos escopetas ${ }^{64}$; el boticario José Martínez ${ }^{65}$, y el mesonero y labrador José Hidalgo, propietario de siete escopetas, aunque de mediocre calidad ${ }^{66}$. Los comerciantes tenían armas en porcentajes cercanos a los anteriores -con un $24,7 \%$ con 929 inventarios y 25,6 \% con 400 documentos-. Sus promedios de número de armas, dos, y de cómputo de tasación, 105 reales, son también casi similares. Destacan, sobre todo, el mercader de paños y sedas Pedro Ramón Bernáldez de Velasco ${ }^{67}$ y el mercader cerero Rafael Igarza, propietario de varias "Armas de fuego" ${ }^{68}$. A la postre, entre los burócratas nos topamos con armas en el 28,5\% de los hogares -con 400 inventarios, el 31,6\%-, un promedio de dos armas y 135 reales de tasación media. Descuellan el administrador general de rentas Domingo Mújica Melgar, con tres escopetas ${ }^{69}$; el sobradero del Hospital del Rey Damián Antón, con tres escopetas ${ }^{70}$, y el mayordomo del Cabildo Catedral Juan Antonio Haedo, con dos escopetas ${ }^{71}$.

El tercer escalón, con más del 30 \% de hogares dotados con armas de caza -con 400 inventarios se disparó hasta el $48.5 \%$-, está ocupado, en exclusiva, por los nobles rentistas, propietarios de dos armas, de promedio -su tasación media se sitúa en los 431 reales de vellón-. Destacan, con luz propia, los aristócratas Bernardo Íñigo Angulo, propietario de cuatro escopetas y tres trabucos ${ }^{72}$; Gonzalo

antiguos de tpo de Carlos Quinto con grano y marcas de oro» (90 reales), "Una Escopeta catalana» (50 reales), "Una Escopetta de Simón y Gaspar con grano de oro» (150 reales). AHPB. JM. Juan Antonio Fernández Guilarte. Legajo 976 (7 de mayo de 1751), folios 19 y 30.

63. El marqués era propietario de «Una Escopeta montada en Pratta con Caja de nogal y dos pistolas correspondientes al mismo género» (1.500 reales), "Una Escopeta Catalana con caja de nogal, mira y puntto de platta" (300 reales), "Una Escopetta con caja de nogal y punto de platta y marcas de oro" (250 reales) y, a la postre, "Una Escopetta corta» (20 reales). AHPB. PN. Francisco Villafranca. Legajo 7095 (17 de marzo de 1763), folio 538.

64. AHPB. PN. Antonio Gil Merino. Legajo 8314 (20 de diciembre de 1769), folio 576.

65. AHPB. PN. Francisco García Penilla. Legajo 6985/3 (10 de septiembre de 1731), folio 52.

66. AHPB. PN. Gregorio Padrones. Legajo 7136 (10 de marzo de 1764), folio 152.

67. AHPB. JM. Juan Antonio Fernández Guilarte. Legajo 976 (12 de septiembre de 1739), folios 14 y 19.

68. AHPB. PN. Feliciano Medel Prada. Legajo 7259/4 (28 de junio de 1787), folio 111.

69. AHPB. PN. José Guadilla. Legajo 7128/2 (26 de noviembre de 1753), folio 108.

70. AHPB. PN. Félix Martín Antón. Legajo 8319 ( 25 de abril de 1785), folio 129.

71. AHPB. PN. Francisco Villafranca. Legajo 7086 (15 de julio de 1746), folio 159.

72. AHPB. PN. Ángel Arnaiz. Legajo 7173 (22 de abril de 1776), folio 241. 
Río Zorrilla, dotado con dos escopetas ${ }^{73}$; Felipe Antonio de Salamanca y Moreda ${ }^{74}$, o Juan Antonio María Enríquez ${ }^{75}$, entre otros.

\begin{tabular}{|c|c|c|c|c|c|}
\hline CUADRO 7 & \multicolumn{5}{|c|}{ ARMAS DE CAZA Y EXTRACCIÓN ESTAMENTAL (S. XVIII) } \\
\hline & TOTAL & HOGARES & & PROMEDIO & PROMEDIO \\
\hline ESTAMENTOS & HOGARES & CON ARMAS & $\%$ & N. ${ }^{\circ}$ ARMAS & TASACIÓN (1) \\
\hline GENERAL & 515 & 64 & 12.4 & 1 & 83 \\
\hline NOBILIAR & 323 & 97 & 30.1 & 3 & 270 \\
\hline ECLESIÁSTICO & 91 & 17 & 18.7 & 2 & 231 \\
\hline TOTAL BURGOS & 929 & 178 & 19.2 & 2 & 200 \\
\hline \multicolumn{1}{|l|}{ (1) En reales de vellón. } & & & & \\
\hline Fuente documental: AHPB. PN. Múltiples Legajos. & & \\
\hline
\end{tabular}

A la postre, vista de manera resumida con el sesgo de lo estamental como fórmula de contraste -véase Cuadro 7-, la posesión de armas de fuego, presumiblemente utilizadas como herramientas cinegéticas, retrata la sociedad del Antiguo Régimen y la Edad Moderna con nitidez. Los nobles disponían de tales armas en el 30,1\% de sus hogares -con un promedio de tres armas, tasadas en 270 reales-. Para los eclesiásticos ello sucede en el 18,7 \% de los hogares -dos armas y 231 reales, de promedio- y, a la postre, el estamento general o "pechero" únicamente disponía de armas de caza en el 12,4\% de los hogares -con, de promedio, entre una y dos armas y una tasación sugerente, 83 reales de vellón, signo inequívoco de la escasa calidad de sus escopetas-.

\section{El DeVEniR de la práctica Cinegética en el Setecientos}

¿Experimentó, a lo largo del siglo XVIII, la práctica de la caza, diagnosticada a través de la posesión de armas de fuego largas en las casas burgalesas, un devenir creciente? A tenor de los cómputos efectuados a partir de las fuentes documentales recopiladas, la respuesta a ese interrogante es afirmativa -véanse Gráfico 1 y Cuadro 8-. No fue un incremento fulgurante ni sorpresivo ni revolucionario. No estamos en una España de revolución industrial ni tan siquiera de revolución industriosa. Es simplemente el sesgo habitual de un Setecientos gradualmente mejorado, aunque no exento de recaídas y tropiezos ${ }^{76}$. En 1700-1720, el $16 \%$ de

73. AHPB. PN. Diego Fernández Cormenzana. Legajo 7075 (27 de noviembre de 1736), folio

74. AHPB. PN. José Guadilla. Legajo 7132 (8 de julio de 1782), folio 698.

75. AHPB. PN. Santiago Romo. Legajo 6980 (17 de junio de 1734), folios 75 y 76.

76. Mantecón Movellán, Tomás. España en tiempos de Ilustración. Los desafíos del siglo XVIII. Madrid: Alianza Editorial, 2013, p. 237. 
los hogares burgaleses poseía algún arma de caza. En 1721-1740, la situación no había cambiado en casi nada (16,1\%). Empero, desde 1741 se observa un evidente incremento, aunque en absoluto explosivo. En 1741-1760, se llega al $21 \%$ de hogares con armas de caza y en 1761-1780 se alcanza el cenit de la centuria con el 22,9 \%. En 1781-1800 se aprecia un ligero retroceso $-21 \%$ de hogares con armas de caza-.

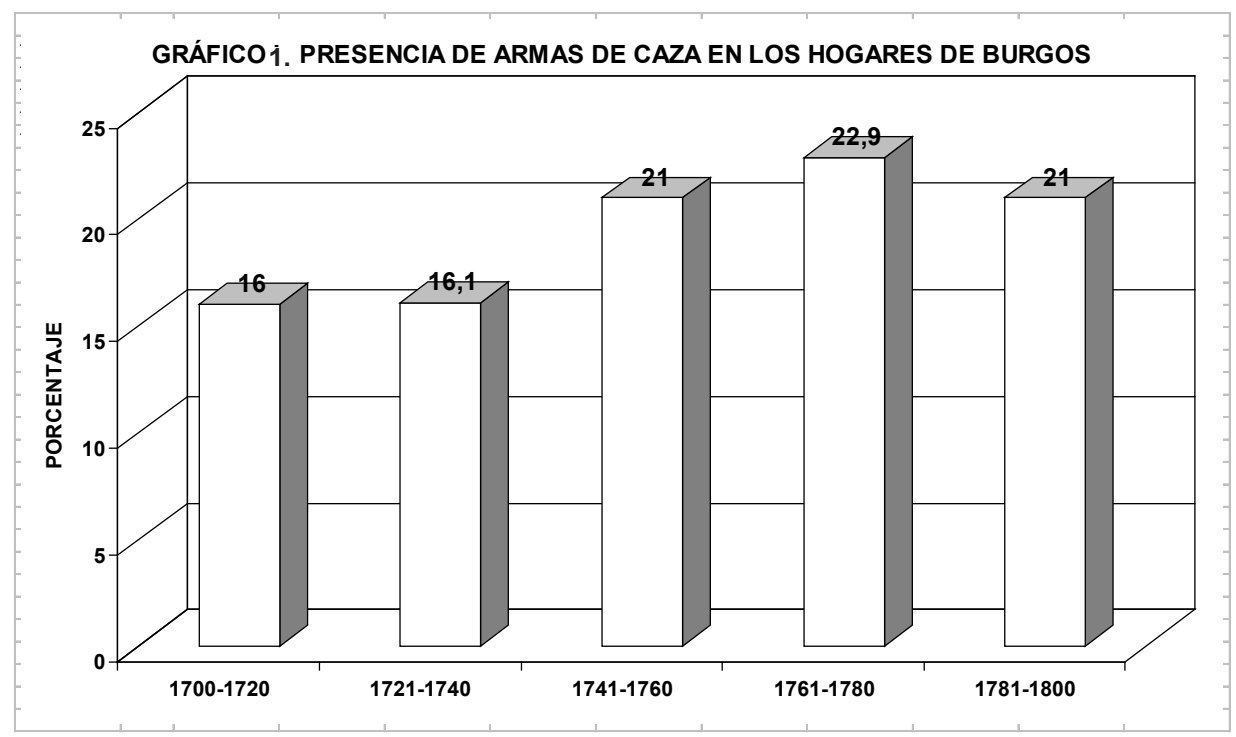

\begin{tabular}{|c|c|c|c|c|c|}
\hline CUADRO 8 & \multicolumn{5}{|c|}{ DEVENIR DE LA POSESIÓN DE ARMAS DE CAZA } \\
\hline & $1700-1720$ & $1721-1740$ & $1741-1760$ & $1761-1780$ & $1781-1800$ \\
\hline TOTAL HOGARES & 218 & 205 & 181 & 192 & 133 \\
\hline HOGARES CON ARMAS & 35 & 33 & 38 & 44 & 28 \\
\hline$\%$ & 16 & 16.1 & 21 & 22.9 & 21 \\
\hline
\end{tabular}

La consideración de la perspectiva global de la implementación de armas largas en las casas burgalesas no debe ocultar, empero, que cada categoría socioprofesional tenía sus peculiares dinámicas. Descuellan, en especial, los comportamientos de nobles rentistas y de eclesiásticos -véanse Gráfico 2 y Cuadro 9-. Por lo tocante a los primeros, los nobles rentistas, su devenir, en los porcentajes de presencia de armas en casa, es contundente. Desde el tímido 20,8 \% de 1700-1720, y el tibio $25 \%$ de 1721-1740, hasta el impactante 61,5\% de 1741-1760. Después se observa un retroceso notable hasta el $47 \%$ de 1761-1780 y el 28,6 \% de 1781-1800. Los eclesiásticos presentan un devenir oscilante. Sobresale el $25 \%$ de 1700-1720; desciende hasta el 
$18.2 \%$ en 1721-1740; remonta hasta el $20.8 \%$ en 1741-1760, e inicia un retroceso, primero leve, hasta el $20 \%$ (1761-1780), y después dramático, hasta el $10 \%$, en 1781-1800. Tal dinámica fue la usual del clero en el Setecientos, sea en lo referente a las $\operatorname{armas}^{77}$ como a sus vestimentas ${ }^{78}$. La mayoría de los eclesiásticos del XVIII irán, progresivamente, asumiendo los dictámenes de Trento y acercándose a estándares más populares y más cercanos a las masas proletarizadas.

Las demás categorías socioprofesionales muestran un devenir más o menos anodino, con excepción de los burócratas -15.8 \% en 1700-1720, 17.2 \% en 1721-1740, 31 en 1741-1760, 37.1 \% en 1761-1780 y $61.5 \%$ en 1781-1800- y los militares -llegados, muy tarde, a la posesión de armas de caza en sus hogares particulares, descubrimos la presencia de armas en el $25 \%$ de ellos en 1741-1760 y del $66.7 \%$ en 1761-1780-. Es igualmente significativo el devenir de los comerciantes, con un excepcional $41.7 \%$ en $1700-1720$ y en torno al $20-25 \%$ en el resto de la centuria -véase Cuadro 9-.

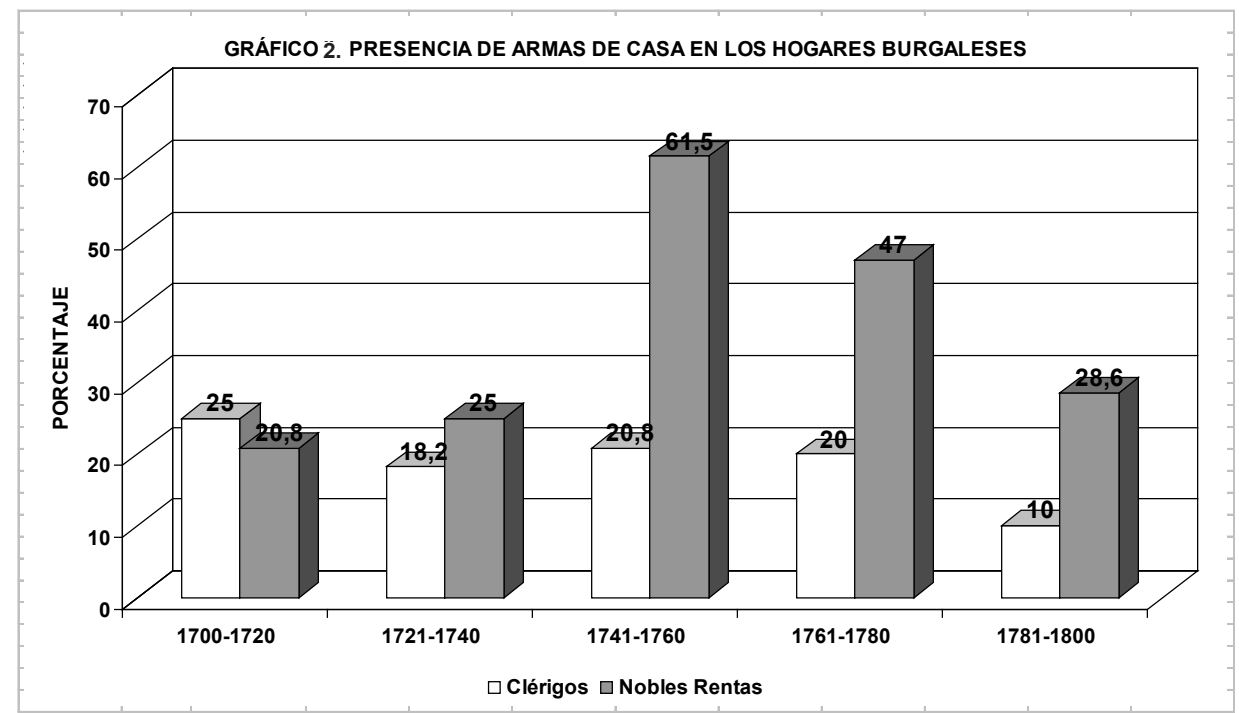

77. Sanz de la Higuera, Francisco. "La caza en el Burgos del Setecientos». Vínculos de Historia, 2015, 4, pp. 251-276, y SANZ DE LA Higuera, Francisco. "Armas en las casas burgalesas del siglo XVIII: Entre la funcionalidad y el exhibicionismo». Studia Historica, Historia Moderna, 2012, 34, pp. 371-406.

78. SANZ DE LA Higuera, Francisco. "La vestimenta del clero en el Burgos del XVIII». Revista de Historia Moderna, 2013, 31, pp. 127-146. 
FRANCISCO SANZ DE LA HIGUERA

ENTRE EL OCIO Y LA NECESIDAD: LA PRÁCTICA DE LA CAZA EN EL BURGOS DEL SETECIENTOS

\begin{tabular}{|c|c|c|c|c|c|}
\hline \multirow{2}{*}{$\begin{array}{c}\text { CUADRO } 9 \\
\text { HILANDERAS }\end{array}$} & \multicolumn{5}{|c|}{ DEVENIR DE LA POSESIÓN DE ARMAS DE CAZA } \\
\hline & $1700-1720$ & $1721-1740$ & $1741-1760$ & $1761-1780$ & $1781-1800$ \\
\hline TOTAL HOGARES & 9 & 13 & 11 & 11 & 4 \\
\hline HOGARES CON ARMAS & & & 1 & & \\
\hline$\%$ & & & 9.1 & & \\
\hline LABRADORES & $1700-1720$ & $1721-1740$ & $1741-1760$ & $1761-1780$ & $1781-1800$ \\
\hline TOTAL HOGARES & 38 & 20 & 35 & 31 & 18 \\
\hline HOGARES CON ARMAS & 4 & 2 & 4 & 3 & 2 \\
\hline$\%$ & 10.5 & 10 & 11.4 & 9.7 & 11.1 \\
\hline ARTESANOS & $1700-1720$ & $1721-1740$ & $1741-1760$ & $1761-1780$ & $1781-1800$ \\
\hline TOTAL HOGARES & 40 & 34 & 29 & 30 & 43 \\
\hline HOGARES CON ARMAS & 5 & 5 & 4 & 2 & 7 \\
\hline$\%$ & 12.5 & 14.7 & 13.8 & 6.7 & 16.3 \\
\hline COMERCIANTES & $1700-1720$ & $1721-1740$ & $1741-1760$ & $1761-1780$ & $1781-1800$ \\
\hline TOTAL HOGARES & 12 & 28 & 14 & 19 & 20 \\
\hline HOGARES CON ARMAS & 5 & 5 & 3 & 5 & 5 \\
\hline$\%$ & 41.7 & 17.8 & 21.4 & 26.3 & 25 \\
\hline BURÓCRATAS & $1700-1720$ & $1721-1740$ & $1741-1760$ & $1761-1780$ & $1781-1800$ \\
\hline TOTAL HOGARES & 38 & 29 & 29 & 35 & 13 \\
\hline HOGARES CON ARMAS & 6 & 5 & 9 & 13 & 8 \\
\hline$\%$ & 15.8 & 17.2 & 31 & 37.1 & 61.5 \\
\hline SERVICIOS PÚBLICOS & $1700-1720$ & $1721-1740$ & $1741-1760$ & $1761-1780$ & $1781-1800$ \\
\hline TOTAL HOGARES & 23 & 29 & 16 & 25 & 7 \\
\hline HOGARES CON ARMAS & 6 & 6 & 3 & 8 & 1 \\
\hline$\%$ & 26.1 & 20.7 & 18.7 & 32 & 14.3 \\
\hline NOBLES RENTISTAS & $1700-1720$ & $1721-1740$ & $1741-1760$ & $1761-1780$ & $1781-1800$ \\
\hline TOTAL HOGARES & 24 & 24 & 13 & 17 & 14 \\
\hline HOGARES CON ARMAS & 5 & 6 & 8 & 8 & 4 \\
\hline$\%$ & 20.8 & 25 & 61.5 & 47 & 28.6 \\
\hline CLÉRIGOS & $1700-1720$ & $1721-1740$ & $1741-1760$ & $1761-1780$ & $1781-1800$ \\
\hline TOTAL HOGARES & 20 & 22 & 24 & 15 & 10 \\
\hline HOGARES CON ARMAS & 4 & 4 & 5 & 3 & 1 \\
\hline$\%$ & 25 & 18.2 & 20.8 & 20 & 10 \\
\hline MILITARES & $1700-1720$ & $1721-1740$ & $1741-1760$ & $1761-1780$ & $1781-1800$ \\
\hline TOTAL HOGARES & 2 & 2 & 4 & 3 & \\
\hline HOGARES CON ARMAS & & & 1 & 2 & \\
\hline$\%$ & & & 25 & 66.7 & \\
\hline Fuente documental: AHF & DN. Múltiples & eqajos (170 & 180 & & \\
\hline
\end{tabular}




\begin{tabular}{|c|c|c|c|c|c|c|}
\hline \multirow[t]{3}{*}{ CUADRO 10} & \multicolumn{6}{|c|}{ DEVENIR DE LAS ARMAS DE CAZA EN EL XVIII } \\
\hline & \multicolumn{2}{|c|}{$1700-1720$} & \multicolumn{2}{|c|}{$1721-1740$} & \multicolumn{2}{|c|}{$1741-1760$} \\
\hline & N. ${ }^{\circ}$ ARMAS & $\%$ & N..$^{\circ}$ ARMAS & $\%$ & N. ${ }^{\circ}$ ARMAS & $\%$ \\
\hline ESCOPETAS & 20 & 9.2 & 30 & 14.6 & 36 & 19.9 \\
\hline TRABUCOS & 6 & 2.7 & 3 & 1.5 & 4 & 2.2 \\
\hline ARCABUCES & 11 & 5.1 & & & & \\
\hline CARABINAS & 3 & 1.4 & 1 & 0.5 & & \\
\hline \multirow[t]{3}{*}{ FUSILES } & 2 & 0.9 & 2 & 0.9 & 1 & 0.6 \\
\hline & \multicolumn{2}{|c|}{$1761-1780$} & \multicolumn{2}{|c|}{$1761-1800$} & & \\
\hline & N. ${ }^{\circ}$ ARMAS & $\%$ & N. ${ }^{\circ}$ ARMAS & $\%$ & & \\
\hline ESCOPETAS & 36 & 18.7 & 25 & 18.8 & & \\
\hline TRABUCOS & 10 & 5.2 & 5 & 3.7 & & \\
\hline \multicolumn{7}{|l|}{ ARCABUCES } \\
\hline CARABINAS & 6 & 3.1 & & & & \\
\hline FUSILES & & & & & & \\
\hline
\end{tabular}

Las armas largas localizadas en los inventarios de bienes presentan derivas también diferentes y contrastables -véase Cuadro 10-. Las escopetas presentan, primero, un panorama escaso, con un $9.2 \%$ de hogares con ellas en 1700-1720; y proseguir, después, con un notable $14.6 \%$ en 1721-1740, hasta el $19.9 \%$ de hogares con escopetas en 1741-1760, e iniciar más tarde un ligero retroceso -el $18.7 \%$ en $1761-1780$ y el $18.8 \%$ en 1781-1800-. Los trabucos tuvieron una titubeante presencia. En 1700-1720 los hallamos en el $2.7 \%$ de los hogares, el $1.5 \%$ en 1721-1740 y el $2.2 \%$ en 1741-1760, para, posteriormente, alcanzar el $5.2 \%-1761-1780-$ y decaer hasta el $3.7 \%$ de presencia en 1781-1800. El arcabuz únicamente lo localizamos en los inventarios de 1700-1721, con un 5.1\% de presencia. La carabina y el fusil estuvieron presentes en gran parte del siglo, pero de una forma muy minoritaria e insegura. La carabina aparece en el 1,4 \% de los hogares en 1700-1720; desaparece, o casi, en las décadas centrales de la centuria, y lo volvemos a encontrar, en 1761-1780, con un significativo $3.1 \%$. El fusil es localizado en el $0.9 \%$ en los primeros 40 años y después decrece hasta el $0.6 \%$ (1841-1760), para, finalmente, desaparecer del todo.

\section{4. ¿DÓNDE CAZAR?}

Una última cuestión, a modo de colofón, está relacionada con el dónde utilizar dichas armas para la práctica cinegética. No podía ser en cualquier paraje y menos en las tierras de cultivo ${ }^{79}$. Lo habitual era que quienes disponían de armas

79. SOSA MAYOR, Igor. El noble atribulado..., pp. 345-366. 
de caza salieran al espacio más cercano a la ciudad ${ }^{80}$. Aunque también eran posibles otras posibilidades. Un ejemplo, modélico, lo encontramos en las explicaciones que el regidor perpetuo, y coronel de infantería, Miguel de la Torre ofrece para justificar no estar presente en algunos Regimientos, «sin haver hecho, antes ni después, más ausencia que la Voluntaria y corttísima de una caza a la Villa de Rabé, dos leguas de esta ciudad " $"$.

En las cercanías de Burgos, en el "Montte perteneciente a la Ciudad que esttá enttre los Lugares de Gamonal y Villafría ${ }^{82}$-plantío de $1599{ }^{83}$, los cazadores, en su mayoría aristócratas y clérigos, disfrutaron de la caza, aunque con limitaciones. Dicho espacio natural fue gestionado por importantes hogares de Burgos, merced al abono de arrendamientos, por nueve años, a los Propios de la Ciudad -Gráfico 3-.

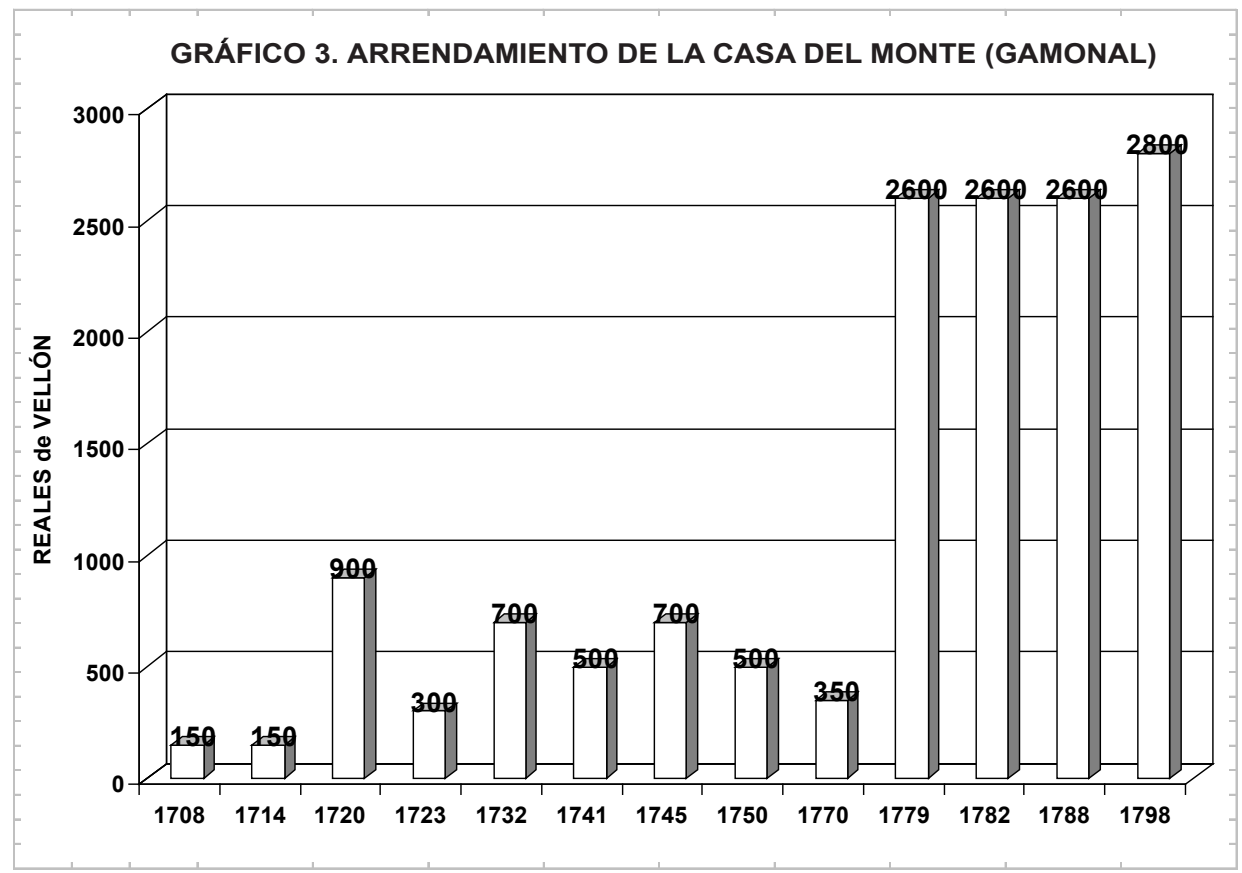

80. Coronas Vida, Luis Jesús. «Montes y arbolado en los pueblos de la jurisdicción de Burgos durante el siglo XVIII. Boletín de la Institución Fernán González, 2006, 232, pp. 179-222.

81. AMB. AG. RO del 26 de septiembre de 1743, folio 252r.

82. Véase, por ejemplo, AHPB. Concejil. José Arcocha. Legajo 82 (6 de junio de 1770), folios 123-128.

83. AMB. Francisco de Nanclares. Legajo HI-1575 (16 de diciembre de 1599). «... esta dha Ciudad, con horden de S.M. [Felipe III], hizo Planttar y Planttó un Montte grande en el Campo de Gamonal». 
En 1708, la "Rentta [de] la Caza de dho montte» se la adjudicó don Antonio Rodríguez de Salamanca, "En la forma Que la tubo el $S^{\text {or }} \mathrm{D}^{\mathrm{n}}$ Benitto Rodríguez de Salamanca, Su Padre» ${ }^{84}$. En 1714, don José Miranda ${ }^{85}$. En 1720, el remate recae en el canónigo del Cabildo Catedral don Juan Cantón Salazar ${ }^{86}$. En 1723, en un racionero de dicho Cabildo, don José Bernáldez de Velasco ${ }^{87}$. En 1732, compitieron por el arrendamiento don Manuel Bermúdez Montes, canónigo de dicha Catedral ${ }^{88}$; un medio racionero capitular, don Juan Jiménez Moreno ${ }^{89}$, y un aristócrata, regidor perpetuo en el Concejo, don Diego de Lerma y Botello, que, finalmente, se adjudicó el remate ${ }^{90}$.

En 1741, el proceso de adjudicación de la «Caza del montte desta ciudad» fue también muy competido. Entraron en liza varios individuos. En primera instancia, don Manuel Robles, beneficiado en Rubena. Se adivinan, incipientemente, algunos problemas ecológicos en el monte, de modo que, "para la maior Seguridad y resguardo de dha Caza», era imprescindible "echar algo de dha Leña para que con la Cortteza de ella se puedan manttener los Conexos». Se imponía "guardar los meses de la veda, los de marzo, abril y maio [...] mediantte allarse dho montte tan aniquilado y apurado de Caza». Se hacía preciso "restaurar la dha Caza y poner el referido Monte en estado del que la pueda produzir para la maior diversión" y "echar en él Cantidad de conexas». De hecho, para "la Conservación de la Caza» dicho clérigo entendía como esencial que "no se a de poder ttirar a los Conexos, guardandose rigurossamente esta prohibicion para que pueda Criarse esta especie de Caza», además de otras especies como "Liebres y perdices». Se detecta, no obstante, «abundanzia de Zorros y ottras Conttra Cazas que conCurren a dho montte» ${ }^{91}$. En segundo término, don Bartolomé de Huidobro ${ }^{92}$. El remate se lo adjudicó, a la postre, don Tomás de Paredes, mercader de joyería ${ }^{93}$. Contra él se alzaron, en 1744, las

84. AMB. AG. RO del 25 de octubre de 1708, folio 310v.

85. Conocemos de ello por AMB. AG. RO del 13 de abril de 1720, folio 95 r.

86. AMB. AG. RO del 4 de marzo de 1720, folio 101r.; RO del 23 de marzo de 1720, folio 78v.; RO del 13 de abril de 1720, folios 94-97, RO del 18 de mayo de 1720, folio 111r.

87. AMB. AG. RO del 20 de marzo de 1723, folios $127 \mathrm{v} .-128 \mathrm{r}$.; RO del 10 de mayo de 1723 , folio 162v.; y RO del 22 de mayo de 1723, folio 170rv.

88. AMB. AG. RO del 9 de junio de 1732, folios 117r.-118v. Su postura fue de 600 reales/año.

89. AMB. AG. RO del 21 de junio de 1732, folios 121v.-122r., y RO del 23 de junio de 1732, folio 128r. (700 reales/año).

90. AMB. AG. RO del 7 de agosto de 1732, folios 179v.-180r.

91. Las citas textuales de este párrafo en AMB. AG. RO del 25 de mayo de 1741, folios 182-185 ( a zien rrs de vellon en cada uno de los ttres primeros años y en los Seis restanttes a rrazon de doscientos reales vellón por cada unom) y RO del 15 de junio de 1741, folios 266-270.

92. AMB. AG. RO del 1 de julio de 1741, folio 284r.-v. ("obligandose a pagar en Cada un año de los ttres primeros años a doscientos y veinte Rs y en los Seis restantes a doscienttos y Zinquentta").

93. AMB. AG. RO del 1 de julio de 1741, folio 284v. ("obligandose a dar en Cada uno de los nueve años trescientos rrs de rentta»); RO del 3 de julio de 1741, folios 287v.-288r., y RO del 17 de julio de 1741, folios 311v.-312r. 
voces airadas de múltiples aristócratas ${ }^{94}$. Estaban escandalizados por la situación de la casa del monte, "deteriorada [y] amenzando Ruina el tejado y escalera de ella». Se plantearon, "antes de que padezca maior daño" y "al mismo que por no haver ninguna Comodidad en ella para poner las Caballerías de los intteresados en la Caza deel Monte por lo reducido deel parage que ay para este fin", un arriendo por 10 años y 700 reales/año. Desalojaron al citado mercader ${ }^{95}$.

En 1750 , se enfrentaron en las posturas el notario Juan Ramírez de Soto ${ }^{96}$ y el mercader de paños y sedas, y criado obrero de la Ciudad, Juan Ramón de Sevilla, en quien se remató el arriendo ${ }^{97}$. El deterioro del monte persistió, hasta el punto de que, en 1769, fue minuciosamente reconocido y se indicó que «se halla Sumamentte detteriorado y pobre de Arvoles, Robres y encinas de que se compone, por desidia de los guardas ha havido y hay en él, y haverse permitido la enttrada a pasttar a ttodo jenero de ganados, mayores y menores». La solución era evidente: "Sean unicamente para el uso de la diversión de la Caza y no para Pasto ni ottro fin alguno" ${ }^{98}$.

El escribano del número José Guadilla asumió el arrendamiento del monte en 1770 por 9 años y 350 reales/año ${ }^{99}$ y en 1779 el marqués de Lorca por 9 años y 2.600 reales/año ${ }^{100}$-Gráfico 3-. Adviértase el desmedido incremento de la renta del monte. El ocio del titulado, y los demás cazadores aristócratas, chocaron con la necesidad de unos vecinos de Villimar, barrio de Burgos, a quienes, en 1782, se "havia cogido cazando con sus Escopetas y al fabor de la luna", ambos reos de la justicia desde ese momento ${ }^{101}$. Ese año el susodicho marqués de Lorca reiteró el arrendamiento a su favor ${ }^{102}$, mientras que en 1788 y 1797 se adjudicó el remate don Antonio García, vecino de Burgos, "por particular encargo de los Señores Lizenciados $\mathrm{d}^{\mathrm{n}}$ Miguel francisco de la Puente y los Tueros, $\mathrm{D}^{\mathrm{n}}$ Laureano

94. Ya sea aristócratas, Don Diego de Lerma Botello, don Bartolomé Sánchez de Valencia, el marqués de Lorca, don Antonio Carrillo, o eclesiásticos, don Juan Manuel Taranco "y otros interesados» -don Gregorio Sota y don Bartolomé Huidobro Garoña-.

95. AMB. AG. RO del 17 de septiembre de 1744, folio 270r.-v. y RO del 22 de marzo de 1745, folios 98v.-99r.

96. AMB. AG. RO del 20 de abril de 1750, folios 96v.-97r. Ofreció 200 reales/año "por la Caza del montte que llaman de gamonal [...] para resguardo y Conserbazión de la caza". En ese momento, la Ciudad denunciaba que "se hallaba mui faltto de Caza dho montte» y era preciso "de quentta de la Ciudad poner persona que Cuide dho montte no solo de la Caza sino de la leña».

97. AMB. AG. RO del 25 de mayo de 1750, folio 122r.-v.

98. AMB. AG. RO del 13 de febrero de 1769, folios 40v.-41r., y RO del 16 de febrero de 1769, folio 53r.-v. "Se cotee el Monte [...] arrendandose, para lo subcesivo, para el uso de la Caza». AMB. JPA. RO del 26 de febrero de 1769, folio 130r.-v.

99. AHPB. Concejal. José Arcocha. Legajo 82 (6 de junio de 1770), folios 123-128.

100. AMB. JPA. RO del 18 de febrero de 17769, folios 26v.-30r.; JPS. RO del 25 de febrero de 1779, folios 34r.-35r.; JPA. RO del 6 de marzo de 1779, folio 41r.-v.; JPA. RO del 23 de marzo de 1779, folios 54r.-56r., y JPA. RO del 8 de abril de 1779, folios 59v.-60r.

101. AMB. AG. RO del 7 de octubre de 1782, folio 243v.

102. AMB. AG. RO del 16 de noviembre de 1782, folios 258v.-260v. -9 años a 2.600 reales/año-. 
de Murga, SS $^{\text {rio }}$ y May ${ }^{\text {mo }}$ del Yll ${ }^{\text {mo }}$ Arzobispo de estte Arzobispado, y d ${ }^{\text {n }}$ Francisco Paula Zorrilla, nal de estta Ciudad», por 2.600 reales/año ${ }^{103}$ y por 2.800 reales/ año ${ }^{104}$, respectivamente.

\section{A MODO DE CONCLUSIÓN}

Sea con una recopilación de 400 inventarios de bienes como con la utilización de 929 documentos -en su inmensa mayoría inventarios post-mortem-, nos acercamos a la disponibilidad de armas de fuego de cañón largo en los hogares de Burgos a lo largo del siglo XVIII, armas susceptibles de ser empleadas eventualmente en la realización de prácticas cinegéticas. Ello es, a mi entender, un hecho probado de manera suficiente.

Los hogares de la ciudad en el Setecientos no habían conseguido acceder a dicho armamento de una manera homogénea. Cuando aparecían entre sus enseres escopetas, trabucos, arcabuces, carabinas o fusiles, las diferencias entre los hogares y las categorías socioprofesionales eran muy significativas, con el telón de fondo de la extracción estamental y los niveles de fortuna. De hecho, los jornaleros estaban excluidos completamente. Los labradores y hortelanos y los artesanos muestran una escasa presencia de tal armamento, posesión sometida, a lo largo del Setecientos, a un devenir cambiante: un primer momento, el primer tercio del siglo, de absoluta ausencia y a un devenir, en los dos últimos tercios, sospechosamente menguante.

Quienes más afición y predisposición tenían, ya fuera por razones lúdicas (de ocio o de ejercicio saludable) o por motivos más épicos (de adiestramiento militar), eran la nobleza rentista, terrateniente y dirigente de la ciudad y los militares de carrera, seguidos, y aquí sí priman puramente los quehaceres de la caza como diversión, por las categorías socioprofesionales más «burguesas», es decir, los comerciantes, las gentes de los servicios públicos y los burócratas, que, salvo excepciones puntuales, conocieron una incorporación gradual y progresiva muy notable a este "mundillo" de las prácticas cinegéticas, fuera por mera emulación hacia los privilegiados o como fórmula reivindicativa de un mayor nivel de comodidad, exquisitez y mejora del poder adquisitivo. Entre unos y otros, los eclesiásticos, contraviniendo un número de hogares significativo, en especial las dignidades y canónigos de la Catedral, sus propias Constituciones Sinodales.

En una sociedad preñada por un poderoso sentimiento de exhibicionismo, propio de una cultura de las apariencias, era imprescindible mostrarse, pública y privadamente, con un atuendo, unos medios de transporte y unos pertrechos directamente representativos de la extracción estamental y los niveles de renta

103. AMB. JPA. RO del 14 de enero de 1788, folios 9v.-10r.

104. AMB. JPA. RO del 20 de enero de 1797, folios 1v.-2r.; JPA. RO del 17 de febrero de 1798, folios 3v.-4r., y JPA. RO del 30 de marzo de 1797, folios 11r.-13r. 
y fortuna a cada uno atribuibles. Las diferencias, abismales, entre los cómputos de tasación, y, por tanto, de los precios de compra -en el mercado de primera o de segunda mano-, y, a la postre, de las materias primas con que se conformaban las escopetas y los complementos de caza, dibujan un panorama, un diagnóstico, sin sorpresas, pero tremendamente clarificador. La caza era una actividad habitual en muchos hogares de las ciudades del Antiguo Régimen. Ya fuera por su derivación gastronómica, a la par que lúdica, o como estrategia de pervivencia del talante señorial y militar, múltiples individuos se echaban a la espalda sus armas de fuego y sus morrales y complementos con el evidente objetivo de adentrarse en la naturaleza, en el monte, y cobrarse un buen número de piezas con las cuales mejorar la calidad de sus mesas y el rango de sus personas.

El Catastro de Ensenada y los protocolos notariales, aun en su inmensidad, han de ser complementados, cuando sea viable y posible -en futuros estudios-, con la utilización de otras fuentes de orden judicial -secuestros de bienes e hijuelas extranotariales- y con información procedente de la legislación borbónica sobre caza, en especial en lo tocante a las prohibiciones a las clases populares y las reglamentaciones de uso a la población en general. Serán muy significativas igualmente las aportaciones derivadas de la literatura, en especial de los pliegos de cordel, los tratados de caza del siglo XVIII y las manifestaciones artísticas en las que aparezcan armas de fuego de la época. Tales incorporaciones darán mucha más consistencia a las reflexiones vertidas en las páginas anteriores y posibilitarán transitar desde un análisis groseramente cuantitativo a una reflexión más cualitativa sobre el armamento doméstico y cinegético, no tan focalizada en la propiedad cuanto decantada funcionalmente hacia los quehaceres de su uso cotidiano o extraordinario, según las circunstancias.

\section{Bibliografía}

Ago, Renata. Il gustto delle cose. Una storia degli oggetti nella Roma del Seicento. Roma: Donzelli Editore, 2006.

Álvarez Santaló, León Carlos y García-Baquero González, Antonio. "La nobleza titulada en Sevilla, 1700-1833. (Aportación al estudio de sus niveles de vida y fortuna)». Historia, Instituciones, Documentos, 1980, pp. 7, 125-167.

Álvarez Santaló, León Carlos y García-BaQuero González, Antonio. "Riqueza y pobreza del clero secular en la Sevilla del Antiguo Régimen (1700-1834)». Trocadero, 1998, 8-0, pp. 11-44.

Álvarez SANTALó, León Carlos y García-BaQuero González, Antonio. «Los comerciantes de la Carrera de Indias en la Sevilla del siglo XVIII: el diseño notarial de sus fortunas y estatus». En García HurTADO, Manuel-Reyes (ed.). Modernitas: Estudios en homenaje al profesor Baudilio Barreiro Mallón, La Coruña: Universidad de La Coruña, 2008, pp. 273-308.

ARDITI, Jorge. A Genealogy of Manners. Transformations of Social Relations in France and England from the XIVth Century to the XVIIIth Century. Chicago y Londres: University Chicago Press, 1998. 
Bartolomé Bartolomé, Juan Manuel. Interiores domésticos y condiciones de vida de las familias burguesas y nobles de la ciudad de León a finales del Antiguo Régimen (1700-1850). León: Universidad de León, 2017.

Baulant, Micheline; Schuurman, Anton y Servais, Paul (eds.). Inventaires après décès et ventes de meubles. Apports à une histoire de la vie économique et quotidienne (XIVe-XIX siècle). Louvain-la-Neuve: Academia, 1988.

BECK, Corinne. "Cases et équipages de chasse en Bourgogne ducale (vers. 1360-1420)». En Paravicini Bagliani, Agostino y Van Der Abeele, Bandonin (coords.). La chasse au Moyen Age. Société, traites, symboles. Florencia: Edizioni del Gallusso, 2000, pp. 151-174.

BraUdel, Fernand. Civilización material, economía y capitalismo. Siglos XV-XVIII. 1. Las estructuras de lo cotidiano. Madrid: Alianza Editorial, 1984, pp. 238-240.

BRUneT, Michel. La chasse et la pêche en Roussillon au XVIIIe siècle. Toulouse: Trabucaire, 1995.

Bustos TORRES, Sara. "Condiciones ofrecidas por los cazadores de Calahorra en el siglo XVII». Kalakorikos, 2015, 20, pp. 73-101.

CADET, Philippe. La chasse sur le litoral de la frontière belge à la baie de Somme, 1713-1914. Arras: Artois Presses Université, 2005.

CARO López, Ceferino. «La caza en el siglo XVIII: sociedad de clase, mentalidad reglamentista». Hispania, 2006, 224, pp. 997-1018.

CatTin, André. Les délits de chasse et leur represión au XVIIIe siècle dans la partie française de l'ancien Évêche de Bâle. Berna La Neuveville: Éditions du Griffon, 1951.

Ciuffoletti, Zeffiro. «La caccia in età moderna in Toscana. Privilegio signorile e conservazione degli habitat». En MalvolTi, Alberto y PINTO, Guiliano (dirs.). Incolti, fiumi, paludi. Uttilizzacione delle ricorse naturali nella Toscana medievale e moderna. Florencia: Olschli, 2003, pp. 237-246.

Convol, André. «Droit de chasse et reserves à l'époque moderne». Dix-septième siécle, 2005, 226, pp. 3-16.

CuestA NieTO, José Antonio. «Los campesinos en Castilla la Vieja, hombres de armas». En Pérez Álvarez, M. ${ }^{a}$ José y Martín García, Alfredo (eds.). Campo y campesinos en la España Moderna. León: Universidad de León, 2013, pp. 793-809.

DANI, Alessandro. "Caccia e pesca tra diritto comune e diritto locale. Il caso della Toscana senese tardo medievale e moderna". Revista di storia del diritto italiano, 1998, 71, pp. 237-271.

De NICOLÓ, Lucía. Le gabicce. Insediamenti, agricultura, caccia, pesca. Secoli XV-XVIII. Villa Verruchio: La Pieve, 2009.

GAlloni, Paolo. Storia e cultura della caccia: Dalla prehistoria a oggi. Bari: Laterza, 2000.

GARCía Fernández, Máximo. "La cultura material doméstica en la Castilla del Antiguo Régimen». En García Fernández, Máximo y Sobaler Seco, M. ${ }^{a}$ Ángeles (coords.). Estudios en homenaje al profesor Teófanes Egido. Valladolid: Junta de Castilla y León, 2004, vol. II, pp. 249-270.

GARCíA Fernández, Máximo (ed.). Cultura material y vida cotidiana moderna: escenarios. Madrid: Sílex, 2013.

García Fernández, Máximo y Dos Guimaraes Sá, Isabel (dirs.). Portas adentro: comer, vestir, habitar (SS. XVI-XIX). Valladolid: Universidad de Valladolid y Coimbra: Universidade de Coimbra, 2010. 
HePp, Freider. "Gar lustig ist die Jägerei. Die kurpfälzer Jagd im 17. und 18. Jahrhundert». En Werner, Thomas (ed.). Jagd-Vergnügen und Verderben. Heidelber: Kurpfälzisches Museum, 1999, pp. 63-83.

HERNANDO SÁNCHEZ, Carlos José. «La gloria del cavallo. Saber ecuestre y cultura caballeresca en el reino de Nápoles durante el siglo XVI». En PINTO Crespo, Virgilio y MarTíneZ Millán, José (dirs.). Felipe II (1527-1598). Europa y la monarquía católica. Madrid: Parteluz, 1998, pp. 277-310.

HERnANDO SÁNCHEZ, Carlos José. «El banquete de damas y caballeros: La corte galante de Carlos V en Nápoles». Bulletin Hispanique, 2017, 119, pp. 427-458.

HuuszKo, Alexis. La chasse au XVIIIe siècle et les capitaineries royales en Ile-de-France. París: Montbel, 2009.

JouAnNA, Arlette. «Die Legitimierung des Adels und die Erhebung in den Adelsstand in Frankreich (16.-18. Jahrhundert)». En ScHulzE, Winfried (ed.). Ständische Gesellschaft und soziale Mobilität. Múnich: Walter de Gruyter, 1988, pp. 165-177.

InGLADA ATARÉs, Jesús. «La caza y la pesca en la Huesca del siglo XVII». Esquinas, 2000, 1, pp. 92-93.

ItKowitz, David. Peculiar Privilege: A Social History Of English Fox Hunting, 1753-1885. Hassocks: Harvester Press, 1977.

IZQUIERDO MARTín, Jesús y SÁNCHEZ LEÓN, Pablo. "Racionalidad sin utilitarismo: La caza y sus conflictos en El Escorial durante el Antiguo Régimen». Historia Agraria, 2001, 24, pp. 123-151.

KNOLL, Martin. Umwelt - Herrschaft - Gesellschaft. Die landesherrliche Jagd Kurbayerns um 18. Jahrbundert. St. Katharine: Scripta Mercaturae Verlag, 2004.

KNOLL, Martin. «Hunting in the Eighteenth Century. An Environmental History Perspective». Historical Social Research, 2004, 3, pp. 9-36.

LADERO QUESADA, Miguel Ángel. «La caza en la legislación municipal castellana: siglos XIII a XVIII. En la España Medieval, 1, 1980, pp. 193-222.

LAGADET, Yann. «Prendre et/ou porter les armes entre les XIIIe et XIXe siècles, un facteur de politisation? Quelques perspectives». Annales de Bretagne et Pays de l'Ouest, 2011, 118(4), pp. 7-20.

LóPez Ontiveros, Antonio. "Caza y actividad agraria en España y Andalucía. Su evolución reciente». Agricultura y Sociedad, 1986, 40, pp. 67-98.

López OnTiveros, Antonio. «Algunos aspectos de la evolución de la caza en España». Agricultura y Sociedad, 1991, 58, pp. 13-51.

López OnTIVERos, Antonio y García Verdugo, Francisco. "Geografía de la caza en España». Agricultura y Sociedad, 1991, 58, pp. 81-112.

Madureira, Nunno L. Cidade: Espaço e quotidiano. Lisboa: Livros Horizonte, 1992.

Mantecón Movellán, Tomás. España en tiempos de Ilustración. Los desafíos del siglo XVIII. Madrid: Alianza Editorial, 2013, p. 237.

Moreno Claverías, Belén. «Pautas de consumo y diferenciación social en El Penedés a fines del siglo XVII. Una propuesta metodológica a partir de inventarios sin valoraciones monetarias». En TORRAS, Jaume y Yun, Bartolomé (eds.). El consumo en la España pre-industrial, Revista de Historia Económica, 2003, n. ${ }^{\circ}$ extraordinario, pp. 207-245.

Moulin, Paul. La chasse en Provence (XIIIe-XVIIIT siècles). Aix Dragon: Cornell University, 1914.

PÉReZ SAmPer, M. ángeles. Mesas y cocinas en la España del siglo XVIII, Gijón: Trea, 2011. 
POPPER, Karl. Conjeturas y refutaciones. El desarrollo del conocimiento científico. Barcelona: Paidós, 1991.

Ramos Palencia, Fernando. Pautas de consumo y mercado en Castilla, 1750-1850. Economía familiar en Palencia al final del Antiguo Régimen. Madrid: Sílex, 2010.

Revilla García, Federico. "La "caza del Rey" en la simbología del siglo XVIII. Boletín del Seminario de Estudios de Arte y Arqueología, 1977, 43, pp. 509-512.

RÖSENER, Werner (ed.). Jagd und höfische Kultur im Mittelalter. Göttingen: Vandenhoek \& Ruprecht, 1997.

RÖSENER, Werner. Die Geschichte der Jagd. Kultur, Gesellschaft und Jagdwesen im Wandel der Zeit. Düsseldorf: Artemis \& Winkler Verlag, 2004.

SAlvadori, Philippe. La chasse sous l'Ancien Régime. París: Libraire Arthème Fayard, 1996.

Sánchez GonzÁlez, Ramón. La caza en Toledo y sus montes durante el Antiguo Régimen. Ciudad Real: Universidad de Castilla-La Mancha, 2003.

SANZ DE LA Higuera, Francisco. «Armas en las casas burgalesas del siglo XVIII: Entre la funcionalidad y el exhibicionismo". Studia Historica, Historia Moderna, 2012, 34, pp 371-406.

SANZ DE la Higuera, Francisco. "La vestimenta del clero en el Burgos del XVIII". Revista de Historia Moderna, 2013, 31, pp. 127-146.

SANZ De la Higuera, Francisco. «La caza en el Burgos del Setecientos». Vinculos de Historia, 2015, 4, pp. 251-276.

SARTI, Rafaella. Vida en familia. Casa, comida y vestido en la Europa Moderna. Barcelona: Crítica, 2002.

SCHWENK, Sigrid. «Von der hohen Kunst zu jagen. Jagdmethoden in 18. Jahrhundert». En Die Jägerey im 18. Jahrbundert. Kolloquium der Arbeistsstelle 18. Jahdhundert. Heidelberg: Bergische Umiversität Gesamthochschule, 1991, pp. 39-47.

Shammas, Carole. The Preindustrial Consumer in England and America. Oxford: Clarendon Press, 1990.

SOBRADO CORREA, Hortensio. "Los inventarios post-mortem como fuente privilegiada para el estudio de la historia de la cultura material en la Edad Moderna». Hispania, 2003, 215, pp. 825-862.

SOSA MAYOR, Igor. El noble atribulado. Nobleza y teología moral en la Castilla moderna (1550-1650). Madrid: Marcial Pons, 2018.

Thompson, Edward Palmer. Whigs and Hunters. The Origin of the Black Act. Londres: Penguin, 1975.

TORRITI, Paolo. "Il príncipe e la caccia nell'arte toscana dal Cinquecento all'Ottocento». En Bonelli Connela, Lucía; Brilli, Attilio y Cantelli, Giuseppe (dirs.). Il paesaggio toscano. L'opera dell'uomo e la nascita di un mito. Cinisello: Bálsamo, 2004, pp. 427-445.

Waro-Desjardins, Françoise. La vie quotidienne dans Le Vexin au XVIIIe siècle. Dans l'intimité d'une société rurale. Condé-sur-Noireau: Éditions du Valhermeil, 1992.

WeATHERILL, Lorna. Consumer Behaviour and Material Culture in Britain, 1660-1760. Londres-Nueva York: Routledge, 1988.

WinkelBauer, Thomas. Fürst und Fürstendiener: Gundaker von Liechtenstein, ein österreichischer Aristokrat des konfessionellen Zeitalters. Viena: Oldenbourg, 1999, pp. 454-455. 